OPEN ACCESS

Edited by:

Xi Wang,

Capital Medical University, China

Reviewed by: Alessandro Poggi, San Martino Hospital (IRCCS),

Kawaljit Kaur, University of California, Los Angeles, United States Jiuwei Cui,

The First Hospital of Jilin University, China

*Correspondence: Yan Wang

yanwang@cicams.ac.cn

Specialty section:

This article was submitted to

Cancer Immunity

and Immunotherapy,

a section of the journal

Frontiers in Immunology

Received: 11 December 2020 Accepted: 15 March 2021 Published: 02 April 2021

Citation:

Yang $Y$ and Wang $Y$ (2021) Role of Epigenetic Regulation in Plasticity of Tumor Immune Microenvironment.

Front. Immunol. 12:640369. doi: 10.3389/fimmu.2021.640369

\section{Role of Epigenetic Regulation in Plasticity of Tumor Immune Microenvironment}

\author{
Yunkai Yang and Yan Wang* \\ State Key Laboratory of Molecular Oncology, National Cancer Center, National Clinical Research Center for Cancer, Cancer \\ Hospital, Chinese Academy of Medical Sciences and Peking Union Medical College, Beijing, China
}

The tumor immune microenvironment (TIME), an immunosuppressive niche, plays a pivotal role in contributing to the development, progression, and immune escape of various types of cancer. Compelling evidence highlights the feasibility of cancer therapy targeting the plasticity of TIME as a strategy to retrain the immunosuppressive immune cells, including innate immune cells and T cells. Epigenetic alterations, such as DNA methylation, histone post-translational modifications, and noncoding RNA-mediated regulation, regulate the expression of many human genes and have been reported to be accurate in the reprogramming of TIME according to vast majority of published results. Recently, mounting evidence has shown that the gut microbiome can also influence the colorectal cancer and even extraintestinal tumors via metabolites or microbiota-derived molecules. A tumor is a kind of heterogeneous disease with specificity in time and space, which is not only dependent on genetic regulation, but also regulated by epigenetics. This review summarizes the reprogramming of immune cells by epigenetic modifications in TIME and surveys the recent progress in epigenetic-based cancer clinical therapeutic approaches. We also discuss the ongoing studies and future areas of research that benefits to cancer eradication.

Keywords: DNA methylation, histone modification, ncRNAs, TIME, ITH, epigenetics

\section{INTRODUCTION}

Cancer is the leading cause of death worldwide and in China and thus remains as the single biggest stumbling block for extending life expectancy. According to GLOBCAN 2018, there are approximately 18.1 million new cancer cases and 9.6 million new cancer deaths worldwide, 24 and $30 \%$ of which occur in China, respectively $(1,2)$. This suggests a large gap between China and other developed countries, such as the United States, in terms of cancer mortality $(1,3)$. Thus, new insights into cancer therapy are necessary for the development of novel strategies and efficacious drug combination therapies.

Tumors are not only a group of abnormally proliferative cells, but also a special environment termed as the tumor microenvironment (TME) that contains different cell types, including tumor and immune cells (4). Owing to the large number of immunosuppressive immune cells, the TME is also called TIME. Thus, developing therapeutic approaches targeting the plasticity of TIME has become one of the most attractive area in cancer therapy. Immune checkpoint inhibition (ICI) is a promising strategy that involves the activation of the function of TIME T cells to combat tumor cells 
$(5,6)$. However, the majority of cancer patients exhibited minimal or no clinical response to ICI therapy (5).

Epigenetic changes in genes encoding tumor suppressors, inhibitory cytokines, and immune checkpoint molecules, e.g., PD-L1 and CD47, can lead to impaired anti-cancer immunity, uncontrollable tumor growth, immune escape, and drug resistance, eventually resulting in tumor development, progression, and metastasis $(7,8)$. Therefore, targeting the epigenetic alterations in cancer cells with epigenetic-associated drugs (epi-drugs) could convert a tumor from an immune suppressive (cold) to an immune permissive (hot) state (9). This could improve the therapeutic effects of other anti-tumor drugs, especially immune checkpoint inhibitors (ICIs). Within the TIME, epigenetic modifications can also be found in tumor-associated immune cells, including myeloid cells, $\mathrm{CD}^{+} \mathrm{T}$ cells, and $\mathrm{CD}^{+} \mathrm{T}$ cells (911). During the differentiation from naïve $\mathrm{CD}^{+} \mathrm{T}$ cells to $\mathrm{CD} 8^{+}$ effector T cells, epigenetic changes, such as DNA methylation and histone modifications, are involved in the chromatin accessibility $(12,13)$. The immune checkpoint protein PD-1 expressed on the surface of exhausted T cells is also regulated by DNA methylation (14). Thus, disrupting the unusual epigenetic regulation in cancer can completely shape the TIME by decreasing the populations of immunosuppressive cells, such as tumor-associated macrophages (TAMs) and myeloid-derived suppressor cells (MDSCs) (15), increasing the numbers of $\mathrm{CD}^{+}$effector $\mathrm{T}$ cells and $\mathrm{NK}$ cells $(15,16)$, elevating the levels of inflammatory cytokines and chemokines (17-19), and upregulating the expression of tumor antigens, such as cancer/testis antigens (CTAs) $(20,21)$.

Tumor heterogeneity, especially intratumor heterogeneity (ITH), is one of the major hallmarks of cancer. Within TIME, there is diversity in the phenotypes of tumor cells and the infiltration and differentiation status of immune cells, and the diversity is characterized by distinct microscopy fields of a single biopsy. Tumor or TIME is formed from a single mutated cell that abnormally proliferates and accumulates additional mutations through Darwinian evolution (22). This may cause drug resistance to cancer therapy, such as in patients with breast cancer, due to pre-existing resistant subclones within the tumor verified by single-cell sequencing technique (23). Aberrant epigenetic changes occur more frequently than gene mutations in human cancer. Thus, targeting the epigenetic changes in cancer may reverse drug resistance to cancer therapies, particularly immunotherapies, and increase the efficacy of other therapeutic approaches that initially failed to achieve durable responses, which is always attributed to ITH (24).

In this review, we summarize the recent knowledge on the role of epigenetic modifications in TIME and ITH. In addition, the latest clinical therapeutic approaches are discussed. These epigenetic alterations may serve as potential targets for more efficacious therapeutic intervention in cancer.

\section{EPIGENETIC MODIFICATIONS}

Epigenetics refers to a special cell events causing heritable phenotypic changes but do not involve alterations in the DNA sequence. Epigenetic modifications involve three different processes, namely DNA methylation, histone modifications, and non-coding RNAs (ncRNAs). They are critical in the regulation of the aberrant expression of tumor-associated genes and encoding of immune checkpoint proteins, tumor suppressors, or oncoproteins in cancer, that contribute to tumor progression and immune invasion (Figure 1). Hence, targeting the dysregulation and dynamic nature of epigenetic alterations provides a new strategy for cancer therapy.

\section{DNA Methylation}

DNA methylation is a biological process in which methyl groups $\left(-\mathrm{CH}_{3}\right)$ from $\mathrm{S}$-adenosylmethionine (SAM) are added to the 5' position of the pyrimidine ring of cytosines in the $\mathrm{CpG}$ dinucleotide called $\mathrm{CpG}$ island. Adenine methylation has been recently observed in mammalian DNA (25), although it has attracted less attention. Gene transcription is silenced when CpG-rich promoters are hypermethylated as these methylated CpGs can impair the binding of transcriptional factors and recruit repressive complexes (26). DNA methylation always represses the expression of tumor-suppressive genes in many types of cancer (27). The process of DNA methylation is mediated by DNA methyltransferases (DNMTs), which include DNMT1, DNMT3a, and DNMT3b $(28,29)$. DNMT2, a homolog of DNMTs, contains all 10 motifs common to all DNMTs. However, DNMT2 can methylate cytosine-38 in the anticodon loop of aspartic acid transfer RNA (tRNAAsp), instead of DNA (30). In gene promoters, DNA methylation occurs in correlation with gene silencing, whereas in other regions, it modulates enhancer activity, gene activation, and splicing $(31,32)$. For example, in the promoter region of the $p d c d 1$ gene, more methylated sites were observed in PD- ${ }^{\text {low }}$ A20 cells than in PD $1^{\text {high }}$ EL4 cells, indicating that DNA methylation occurring in the promoter region silences the expression of $\mathrm{PD}-1$ in $\mathrm{T}$ cells (14).

5-methylcytosine $(5 \mathrm{mC})$ can be removed via oxidation catalyzed by ten-eleven translocation (TET) methylcytosine dioxygenases (TET1, TET2, and TET3), resulting in generation of 5-hydroxymethylcytosine $(5 \mathrm{hmC}), 5$-carboxycytosine $(5 \mathrm{caC})$, 5 -formylcytosine $(5 \mathrm{fmC})$, and unmethylated cytosine $(33,34)$. DNMTs and TETs regulate the gene activation and repression, together maintaining the stability of gene transcription under certain circumstances. Once this balance is interrupted, many genes are abnormally silenced or activated, leading to various pathological conditions, especially cancer (35). In patients with primary breast cancer (PBC) and colorectal cancer (CRC), immune checkpoint proteins PD-L1, CTLA-4, TIGIT and TIM-3 are significantly upregulated with the hypomethylation of promoters because of upregulated TET2 and TET3 (36). The increased levels of immune checkpoint molecules may be one of the causes of repressed activation and function of immune cells in the TIME.

In a pan-cancer analysis result, researchers found that the global loss of DNA methylation is negatively correlated with host immune pathways, including antigen processing and presentation, cytokine-cytokine receptor interaction, and major histocompatibility complex (MHC) (37). In the same study, DNA demethylation has a positive correlation with 


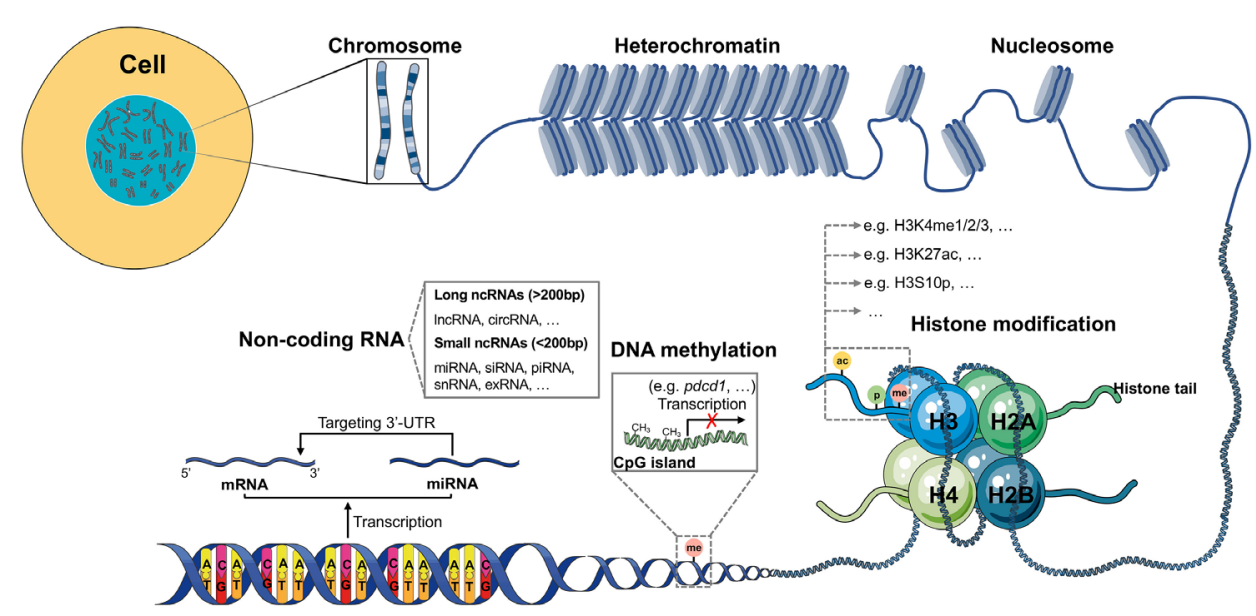

FIGURE 1 | Schematic model of epigenetic regulation. The expression of most human genes is regulated by epigenetic modifications. There are three different epigenetic processes that control gene transcription and expression: DNA methylation, histone modification and ncRNA. DNA methylation always exists in GC-rich areas of the human genome called CpG islands, which can be methylated by DNMTs, resulting in failed transcription of genes, such as pdcd1. Histone modification, in which amino acids on four different histone tails (H2A, H2B, H3, H4) can be modified by different enzymes (KMTs, HATs, phosphatases, KDMs, HDACs, among others), results in the regulation of gene expression. In the human genome, many DNA sequences cannot be transcribed into mRNAs but are transcribed as ncRNAs. According to the length, ncRNAs can be divided into small and long ncRNAs. The most investigated ncRNA is miRNA, which targets the 3'-UTR of mRNA, thus contributing to gene silencing.

genomic mutation burden and aneuploidy level, which contributes to tumor cell proliferation (37). Therefore, DNA methylation-modifying agents can be potentially used for cancer therapy or the improvement of the efficacy of cancer immunotherapy. DNA methylation also acts as a modulator of immune cells differentiation. Datasets from the BLUEPRINT Epigenome Project (http://www.blueprint-epigenome,eu) reveal that the global methylation level increases during macrophage differentiation and activation, whereas it acts in an opposite way in $\mathrm{T}$ and $\mathrm{B}$ cells (38).

\section{Histone Modifications}

There are two types of histones: core histones H2A, H2B, H3, H4 and linker histone H1. They can be modified by proteins called "readers," "writers," and "erasers" at the histone tails. The nucleosome core comprises two $\mathrm{H} 2 \mathrm{~A}-\mathrm{H} 2 \mathrm{~B}$ dimers and an $\mathrm{H} 3-$ $\mathrm{H} 4$ tetramer. The most frequent histone modifications are methylation, acetylation, and phosphorylation; however, there exist other modifications, including citrullination, ubiquitination, ADP-ribosylation, deamination, formylation, O-GlcNAcylation, propionylation, butyrylation, crotonylation, proline isomerization, and lactylation (39-41). All of these modifications not only activate or repress gene transcription, but also influence several processes, such as DNA repair, DNA replication, and recombination (40). Once histone modifications are aberrantly regulated, the steady state of the cell is disrupted, and diseases, such as cancer initiate, develop, and progress.

\section{Histone Methylation}

Unlike DNA methylation, histone methylation involves the addition of methyl groups to mainly lysine (K) (mono-, di-, or trimethylated) and arginine ( $\mathrm{R})$ residues (mono- or dimethylated) in the histone tails, which mediate gene transcription, including those cancer progressive and immunosuppressive genes. The six major families of histone lysine methyltransferase complexes (KMT1-6) are responsible for the methylation of lysine residues, mainly on histone $\mathrm{H} 3$, followed by $\mathrm{H} 4(42,43)$. The methyl groups added to lysine residues by KMTs can be removed by lysine demethylases (KDMs), which contains six families (KDM1-6) at least (8). The distinct sites or degrees of lysine methylation on histones determine the activation or silencing of many genes. For instance, methylation at lysine 4 on histone $\mathrm{H} 3$ $(\mathrm{H} 3 \mathrm{~K} 4 \mathrm{me} 1 / 2 / 3)$ and $\mathrm{H} 3 \mathrm{~K} 36 \mathrm{me} 2 / 3$ are always involved in the activation of gene transcription, whereas that on $\mathrm{H} 3 \mathrm{~K} 9 \mathrm{me} 3$ and H3K27me3 exert the opposite function $(8,44)$. The loss of H3K79me2 in TIME contributes to tumor progression in a mouse model (45). Many immune cell types, such as macrophages, dendritic cells (DCs), and natural killer cells (NKs), can also be regulated by histone methylation in cancer (46-48).

\section{Histone Acetylation}

Histone acetylation is involved in the activation of gene transcription by attenuating interactions between histones and DNA via the addition of an acetyl group $\left(-\mathrm{CH}_{3} \mathrm{CO}\right)$ from the acetyl coenzyme A (acetyl-CoA) to the $\alpha / \epsilon$-amino group of lysine side chains, as it neutralizes the positive charge $(40,41$, $49,50)$. The reversible addition and removal of acetyl groups are catalyzed by histone acetyltransferases (HATs) and histone deacetylases (HDACs) (51). There are two types of HATs (type-A and type-B) found in the human genome, of which, type-B HATs can only acetylate newly synthesized histones, such as $\mathrm{H} 4$ at $\mathrm{K} 5$ and $\mathrm{K} 12$, but not those deposited in the chromatin $(40,52)$. The well-studied and major families of HATs in humans 
include GNAT (HAT1, GCN5, and PCAF), MYST (Tip60, MOF, MOZ, MORF, and HBO1), and p300/CBP (53). On the other hand, the loose chromatin mediated by HATs can be restabilized by HDACs, resulting in transcriptional silencing. HDAC1, a component of the NuRD complex, mediates the histone deacetylation of $\mathrm{H} 3 \mathrm{~K} 27$ in the promoter region of STAT1, which downregulates STAT1 expression, resulting in type I IFN suppression in TIME (54). HDACs can be classified into four groups (I, II, II, and IV) (53). HDACs, as potential cancer therapeutic targets, have attracted increasing attention due to their role in cancer epigenetics and disease development. Currently, there are four FDA-approved HDAC inhibitors: Vorinostat (SAHA) and Istodax (romidepsin) have been approved for the treatment of cutaneous T-cell lymphoma (CTCL) in 2006 and 2009, respectively; Beleodap has been approved for the treatment of peripheral T-cell lymphomas (PTCL) in 2014; and Panobinostat has been approved for the treatment of patients with multiple myeloma (MM) in 2015 (55). HDAC inhibitors have multiple functions in immunomodulatory activities, including the promotion of the expression of MHC I molecule, tumor antigens, PD-L1, and T cell chemokines, induction of immunogenic cell death hallmarks in tumor cells, and decreasing Treg cells $(13,56,57)$. Metabolites, such as butyrate and propionate, produced by the gut microbiome can also inhibit the activity of HDACs (58).

\section{Histone Phosphorylation}

Histone phosphorylation, another post-transcriptional modification (PTM) event, occurs mainly at the serine (S), threonine (T), and tyrosine (Y) sites of histone tails and regulates the transcription of genes that are involved in cell cycle and proliferation $(27,59)$. Histone phosphorylation is correlated with the proliferation and progression of many types of cancer. For instance, decreased H3S10p levels were observed in MDA-MB-231 cells treated with the microRNA941 inhibitor, which suggests that $\mathrm{H} 3 \mathrm{~S} 10 \mathrm{p}$ has a potential role in promoting the proliferation of MDA-MB-231 cells (60). The tyrosine 39 of histone H2A.X can be phosphorylated by JMJD6, which leads to triple-negative breast cancer (TNBC) cell growth (61). In castration-resistant prostate cancer (CRPC), researchers have found that histone phosphorylation is positively correlated with cancer cells progression and drug resistance, and its blockade inhibits tumor growth in a CRPC mouse model (62).

\section{Non-Coding RNAs}

RNAs that are not translated into proteins are termed as ncRNAs, which represent about $90 \%$ of human genomederived RNAs and contain small ncRNAs, such as microRNAs (miRNAs), small interfering RNAs (siRNAs), PIWI-interacting RNAs (piRNAs), small nuclear RNAs (snRNAs), extracellular RNAs (exRNAs), circular RNAs (circRNAs), and long noncoding RNAs (lncRNAs), such as Xist $(27,63)$. Small ncRNAs are less than $200 \mathrm{bp}$ in length, whereas circRNAs and lncRNAs are more than $200 \mathrm{bp}$ in length (27). The aberrant expression of ncRNAs is always associated with many diseases, including cancer. One of the most widely studied ncRNAs is miRNAs, which are nearly 20 bases long and mediate the cleavage and degradation of mRNAs by targeting the 3'-untranslated region (3'-UTR), thereby leading to translation failure (64).

Thousands of miRNAs have been found to regulate $>30 \%$ of human genes engaged in the cell cycle, and cell proliferation, differentiation, or apoptosis (65-67). Some miRNAs can act as tumor suppressors by targeting immune checkpoint molecules, such as PD-L1, PD-1, CTLA-4, and TIM-3, in tumor cells, such as ovarian cancer, prostate cancer (PC), and non-small cell lung carcinoma (NSCLC) or immune cells, such as T cells and DCs in the TIME (8). In a glioma mouse model, miR-138 treatment is positively associated with median survival time and negatively correlated with tumor regression (68). While some other miRNAs participate in tumor development. For example, the elevated expression of miR-1269 promotes the formation and progression of gastric cancer and suppresses cell apoptosis by modifying the AKT and Bax/Bcl-2 signaling pathways (69). The overexpression of miR-9 has been confirmed in glioma cells and reported to significantly improve their migration and invasion by targeting COL18A1, THBS2, PTCH1, and PHD3 (70). In cancer immunity, the function of immune cells can also be suppressed by miRNAs (71).

Moreover, emerging evidence has shown that lncRNAs have multiple functions in regulation of cell proliferation, migration, invasion, and apoptosis in cancer progression (72-74). Additionally, lncRNAs may be pivotal regulators of TIME remodeling via several mechanisms, including the induction of Treg cells, inhibition of recruitment of macrophages, activationinduced cell death (ACID) of T lymphocytes, and the activation of $\mathrm{Ca}^{2+}$-triggered signaling (75-78).

\section{REPROGRAMING OF IMMUNE CELLS IN TIME}

One of the biggest obstacles to cancer therapy is tumor escape from the host immune system. Tumor cells tend to modify the microenvironment around themselves by recruiting and educating immune cells, thereby forming an immunosuppressive area termed as TIME. Immune cells, including innate immune cells and $\mathrm{T}$ cells, support tumor expansion via various mechanisms, and the critical role of the epigenetic reprograming of these immune cells has been revealed (Figure 2). A multi-platform genome-wide dataset of various types of sarcoma demonstrated the correlation between epigenomic alterations and the infiltration of immune cells into the TIME (79).

\section{Innate Immune Cells}

Macrophages are a type of white blood cells of the innate immune system that engulf and digest non-self substrates such as cancer cells in a process called phagocytosis. They have also been shown to contribute to tumor growth and progression after epigenetic modification into TAMs, the major infiltrating leukocytes in most malignant tumors. Research groups from the MD Anderson Cancer Center have performed gain-offunction screening of epigenetic regulators in an inducible 


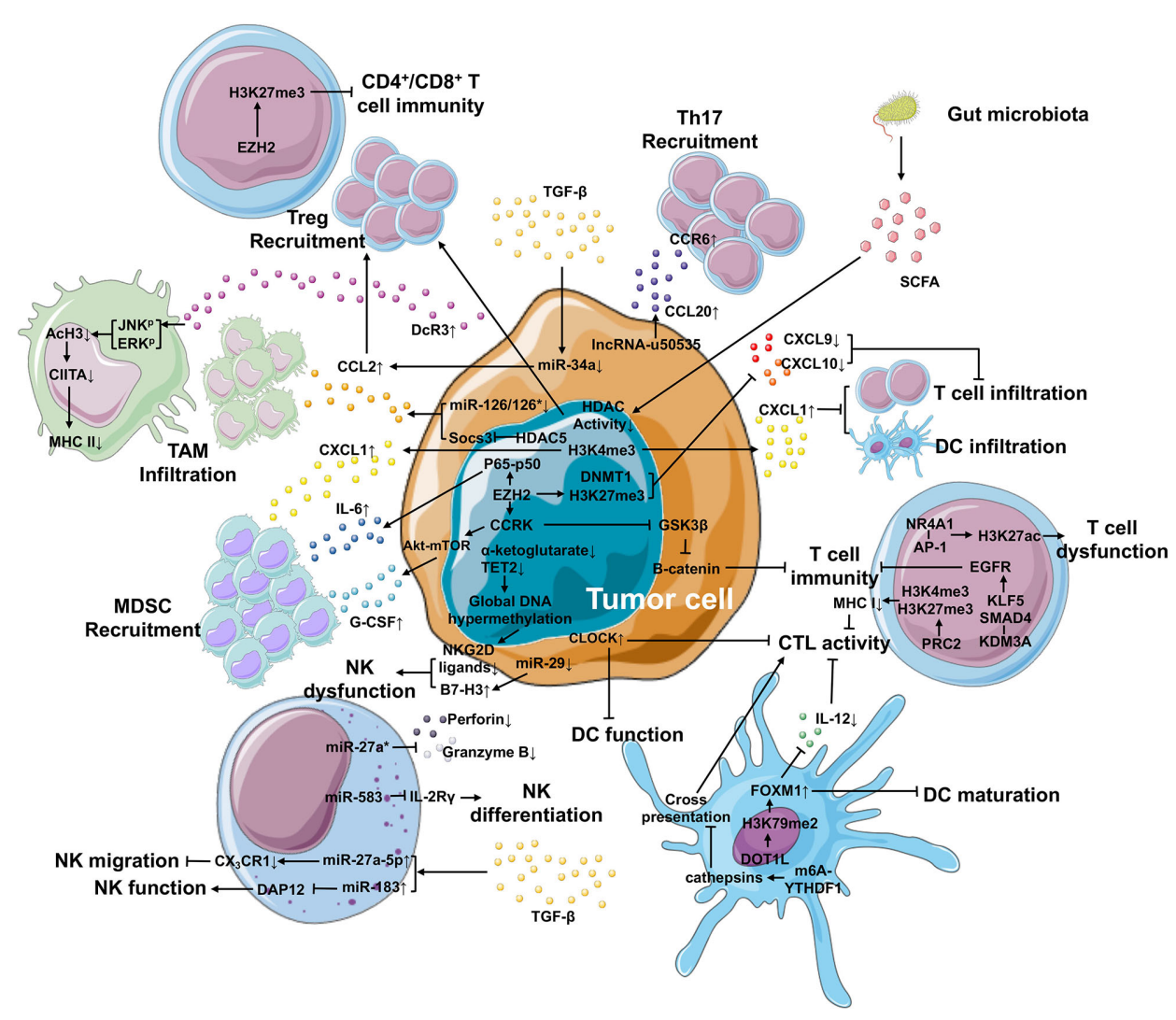

FIGURE 2 | Epigenetic mechanisms in the TIME that contributes to cancer development. Within the TIME, epigenetic regulation plays an important role in generating immunosuppressive environment and facilitating tumor differentiation. In tumor cells, epigenetic regulation is involved in the upregulation of IL-6 and G-CSF and the downregulation of CXCL9 and CXCL10 via EZH2, as well as the elevated expression of CXCL1 secreted by tumor cells via H3K4me3, leading to improved MDSC recruitment and repressed T cell or DC infiltration, respectively. The expression of CCL2 (responsible for the recruitment of TAM and Treg cells) and CCL20 (responsible for Th17 recruitment) is enhanced by miR-126/126* or miR-34a and IncRNA-u50535, respectively. Furthermore, tumor cells can suppress the function of macrophage-, NK cell-, DC- and T cell-mediated immunity through other epigenetic mechanisms. In the TIME, high TGF- $\beta$ levels can be produced by not only tumor cells, but also other cell types. TGF- $\beta$ can regulate the expression of miRNAs in tumor cells and NK cells, suppressing NK migration and function and Treg recruitment. What's more, the gut microbiota releases SCFA that inhibits the activity of HDACs, further improving the recruitment of Treg cells.

$\operatorname{Kras}^{\mathrm{G} 12 \mathrm{D}}$ p53 null pancreatic ductal adenocarcinoma (PDAC) mouse model and identified that HDAC5 mediates the upregulated expression of chemokine CCL2 by repressing Socs3, resulting in the recruitment of TAMs, which subsequently enables $\mathrm{KRAS}^{*}$-independent tumor growth (80). CCL2 expression is regulated by miR-126/126* in breast cancer cells. Downregulated miR-126/126* by promoter methylation of their host gene Egfl7 mediates CCL2 upregulation (81). Finally, elevated CCL2 recruit macrophages to promote breast cancer metastasis. MHC II molecules on the surface of macrophages mediate antigen presentation, which is important for the induction of adaptive immune responses. In patients with pancreatic cancer, ERK and JNK induce histone deacetylation at the promoter region of the class II transactivator (CIITA), leading to decoy receptor (DcR3)-mediated downregulation of MHC II expression (82). The loss of MHC II expression impairs the antigen presentation, resulting in TAM-induced immunosuppression (82). The differentiation and polarization of macrophages can also be modulated by the enhancer of zeste homolog 2 (EZH2) (83), a histone methyltransferase and the catalytic subunit of polycomb repressive complex 2 (PRC2), indicating that $\mathrm{EZH} 2$ is involved in the reshaping of TIME.

MDSCs $\left(\mathrm{CD} 1 \mathrm{~b}^{+} \mathrm{Gr}^{+}\right)$are a heterogeneous group of immune cells from the myeloid lineage and possess strong immunosuppressive activities in cancer. In breast cancer patients, MDSC levels in the blood are approximately 10-fold higher than healthy individuals (84). Their expansion into the TIME is negatively correlated with poor survival rates due to inhibited $\mathrm{CD}^{+} \mathrm{T}$ cell proliferation in hepatocellular carcinoma (HCC) (85). In the same study, upregulated EZH2 interacts with the phosphorylated NF- $\kappa \mathrm{B}$ subunit p65, and the EZH2-NF- $\mathrm{BB}$ complex binds to the $I L-6$ promoter to enhance the expression of IL-6, thereby subsequently inducing MDSC recruitment to the TIME (85). In another study, the Akt-mTOR signaling pathway has been shown to trigger the recruitment of MDSCs to promote tumor initiation (86). And Akt phosphorylation can be mediated by cell cycle-related kinase (CCRK), whose expression can be regulated by EZH2 (87). These findings suggest that MDSCs can 
be recruited through distinct mechanisms associated with epigenetic modifications, especially those mediated by EZH2.

DCs are professional antigen-presenting cells (APCs) and act as messengers between the innate and adaptive immune systems. However, their antigen-presenting capacity is abolished in many solid tumors owing to their immature state and low levels of IL-12 production. Mechanistically, forkhead box M1 (FOXM1) expression is enhanced by $\mathrm{H} 3 \mathrm{~K} 79 \mathrm{me} 2$ that is present in both tumor cells and DCs, which causes abnormal maturation phenotypes of DCs and decreased production of IL-12 in tumorbearing mice with pancreatic and colon cancers (47). Furthermore, H3K79 is methylated by DOT1-like histone lysine methyltransferase (DOT1L) and the inhibition of DOT1L not only decreased H3K79me2, but also downregulated FOXM1 expression and reversed the immunosuppressive state (47). FOXM1 is reported to be associated with cancer proliferation, angiogenesis, EMT, migration, metastasis, and stemness in many types of cancer (88). A recent study has revealed that the RNA N6methyladenosine $\left(\mathrm{m}^{6} \mathrm{~A}\right)$ modification is correlated with TIME infiltration in gastric cancer (89). In DCs, the $\mathrm{m}^{6} \mathrm{~A}$ modification mediated by RNA methyltransferase Mettl3 in the transcripts of CD40, CD80, and TLR4 signaling adaptor Tirap promotes the activation and function of DCs and DC-based T cell response (90). Han et al. have reported that the binding of YTH N6methyladenosine RNA binding protein 1 (YTHDF1) to the transcripts encoding lysosomal proteases modified by $\mathrm{m}^{6} \mathrm{~A}$ methylation improved the translational efficiency of lysosomal cathepsins in DCs, whereas the suppression of cathepsins in DCs significantly strengthened its ability to cross-present tumor antigens, which in turn enhanced the tumor infiltrating $\mathrm{CD}^{+} \mathrm{T}$ cell antitumor response (91). Through screening of known epigenetic regulators, the circadian locomotor output cycles kaput (CLOCK), a circadian regulator possessing potential histone acetyltransferase activity, has been shown to have a negative correlation with the function of $\mathrm{CD}^{+}$activated $\mathrm{T}$ cells and DCs in glioblastoma (GBM) (92). However, further studies are needed to elucidate the epigenetic regulation mechanism of CLOCK in TIME.

NK cells are cytotoxic lymphocytes critical to the innate immune system. Their role is analogous to that of cytotoxic $\mathrm{T}$ lymphocytes (CTLs), which recognize target cells such as cancer cells upon the expression of non-self HLA antigens. NKG2D ligands (ULBP1 and ULBP3) on tumor cells are downregulated via DNA methylation, resulting in the escape of IDH1 and IDH2 mutant gliomas from NK cells (93). IDH1 and IDH2 mutations cause global DNA hypermethylation because of decreased $\alpha$ ketoglutarate levels and TET2 function in many cancer types, including acute myelogenous leukemia (AML) (93). The cytotoxicity of NK cells is also regulated by miRNAs. It is well known that B7-H3, a surface glycoprotein, exerts inhibitory effects on NK cells, which abolishes the anti-tumor activity of these cells (94). The downregulation of miR-29 expression in cancer contributes to the B7-H3 upregulation, leading to NK cell dysfunction and tumor immune escape $(95,96)$. Perforin (Prf1) and granzyme $\mathrm{B}(\mathrm{GzmB})$ are key cytotoxic effectors that kill cancer cells for NKs. However, miR-27a* reverses the cytotoxicity of NK cells by silencing Prf1 and GzmB expression
(97). Because Prf1 and GzmB are the functional effectors of CTLs, the cytotoxic capacity of CTLs may also be inhibited by miR-27a*. Using a genome-wide mRNA and miRNA database, Yun et al. identified that miR-583 targets the 3'-UTR of the IL2 receptor gamma (IL2R $\gamma$ ) and acts as a negative regulator of $\mathrm{NK}$ cell differentiation (98). The activity of NK cells is strongly repressed by TGF- $\beta$, an immunomodulatory cytokine that is released in the TIME. TGF- $\beta$ induces the overexpression of miR27a-5p, which targets 3'-UTR of the chemokine receptor $\mathrm{CX}_{3} \mathrm{CR} 1$ expressed in several immune cells, resulting in the suppression of the migration ability of NK cells (99). Another TGF- $\beta$-induced miRNA is miRNA-183. The miR-183 binds and suppresses the DNAX activating protein $12 \mathrm{kDa}$ (DAP12), an adaptor protein critical for NK cells, to inhibit NK cell function, thus creating an immunosuppressive TIME (100).

\section{T Cells}

The key effector cells for tumor eradication are the CD8+ cytotoxic $\mathrm{T}$ cells because they directly recognize and kill cells displaying foreign antigens through binding MHC I molecules. The loss of MHC I expression in tumor cells abolishes antigen presentation, thereby contributing to immune evasion. A genomewide CRISPR/Cas9 screen was performed and identified that PRC2, a complex with histone methyltransferase activity, silences the expression of MHC I via bivalent $\mathrm{H} 3 \mathrm{~K} 4 \mathrm{me} 3$ and H3K27me3 modifications and inhibits the anti-tumor immunity mediated by $\mathrm{T}$ cells (101). Simultaneously, the existence of bivalent $\mathrm{H} 3 \mathrm{~K} 4 \mathrm{me} 3$ and $\mathrm{H} 3 \mathrm{~K} 27 \mathrm{me} 3$ at the MHC I promoter region in a range of human MHC I-deficient cancers was detected (101). Thus, targeting bivalent H3K4me3 and $\mathrm{H} 3 \mathrm{~K} 27 \mathrm{me} 3$ may be one of the potent therapeutic approaches in cancer treatment. Another in vivo CRISPR screen in a PDA mouse model identified that KDM3A potentially blocks T cell-mediated immune response via regulating the expression of epidermal growth factor receptor (EGFR) through the Krueppel-like factor 5 (KLF5) and SMAD family member 4 (SMAD4) (102), which makes KDM3A a potential target for cancer therapy.

ICI therapy for various cancers has revolutionized the standard of care and achieved significant clinical outcomes. Nevertheless, only a limited subset of patients harbors positive feedback after ICI treatment (103). The main reason for this is that the expression of immune checkpoint molecules/ligands is always regulated by epigenetic alterations, including DNA methylation, histone modification, and ncRNAs. Epigenetic regulation of immune checkpoint proteins on $\mathrm{T}$ cells can lead to an immunosuppressive TIME through the following effects: less responsive T cells, increased Treg cells, MDSC recruitment, and impaired release of effector cytokines (104). The Cancer Genome Atlas (TCGA) Level 1 methylation data from 30 solid tumor types have revealed that hypermethylated costimulatory genes and hypomethylated immune checkpoint genes are negatively associated with functional $\mathrm{T}$ cell recruitment to the TIME (105). To promote the therapeutic efficacy of ICI treatment, methods that can be used to restimulate the expression of immune checkpoint proteins and costimulatory molecules are one of the solutions in cancer therapy. 
As mentioned above, EZH2 epigenetically upregulates the expression of CCRK, and CCRK inactivates GSK3 $\beta$ via phosphorylation, thus further activating $\beta$-catenin in HCC cells $(87,106)$. In addition, $\beta$-catenin signaling in melanoma samples is correlated with the absence of a T cell gene expression signature (107). These results suggest a relationship between EZH2 and $\mathrm{CD}^{+} \mathrm{T}$ cell infiltration within the TIME in melanoma. Regarding to $\mathrm{T}$ cell infiltration, CXCL1 overexpression in PDA tumors can diminish the number of infiltrated T cells (108). In this study, a library of congenic cell clones from KPCY tumors was established, and the immune microenvironment was analyzed. In brief, they found that H3K4me3 modification at the Cxcll promoter enhances the expression of CXCL1 in PDA tumor cell clones, leading to low infiltration of T cells and DCs, and the recruitment of MDSCs, which shapes the TIME and influences the outcome of immunotherapy (108). Effector T-cell trafficking to the TIME is mediated by $\mathrm{T}$ helper $1\left(\mathrm{~T}_{\mathrm{H}} 1\right)$-type chemokines CXCL9 and CXCL10. Whereas, in a human ovarian cancer model, H3K27me3 induced by EZH2 and DNA methylation catalyzed by DNMT1 at their promoter regions repress the expression of CXCL9 and CXCL10 in tumor cells (109). Furthermore, the expression of EZH2 and DNMT1 in tumors is negatively correlated with $\mathrm{CD}^{+} \mathrm{T}$ cell infiltration within the TIME, as well as patient prognosis (109). Therefore, EZH2 can serves as a cancer therapeutic target. Infiltrated T cells may be dysfunctional because of different mechanisms, which may include nuclear receptor subfamily 4 group A member 1 (NR4A1) regulation. NR4A1 is highly expressed in tolerant $\mathrm{T}$ cells and can bind to activator protein $1(\mathrm{AP}-1)$ to promote $\mathrm{H} 3 \mathrm{~K} 27 \mathrm{ac}$, which leads to the activation of tolerance-related genes (110).

In the healthy state, Treg cells play a pivotal role in maintaining host immune homeostasis. However, in HCC tumors, TGF- $\beta$ stimulation leads to the low expression of miR34a, upregulates CCL2 and finally recruits more Treg cells to the TIME (111). EZH2, an important methyltransferase, is considered as a potent therapeutic target in many cancers. The distinct expression level of EZH2 in Treg cells depends on their locations. Particularly, Treg cells in tumor tissues specifically express high levels of EZH2 and its histone modification H3K27me3 compared with those in non-lymphoid tissues, resulting in tumor tolerance (112). In addition, the EZH2 and H3K27me3 levels are increased only in Treg cells when compared to $\mathrm{CD}^{+}{ }^{+}$Foxp3 $3^{-} \mathrm{T}$ cells in tumor tissues (112). Targeting EZH2 in Treg cells remodels the TIME by improving recruitment and function of $\mathrm{CD} 4^{+}$and $\mathrm{CD} 8^{+}$ effector $\mathrm{T}$ cells that guide antitumor immunity (112). The presence of Th17 cells (a group of $\mathrm{CD}^{+} \mathrm{T}$ cells characterized by ROR $\gamma$ expression and IL-17 production) in the TIME is correlated with poor prognosis in colorectal cancer patients. Th17 cells can be recruited to the TIME via the CCR6-CCL20 pathway in cervical cancer due to upregulated CCL20 in tumor tissues and high expression of CCR6 on Th17 cells aggregated within tumor tissues (113). It is a possible that Th17 cells are recruited into the TIME via the CCR6-CCL20 axis, thereby contributing to the IncRNA u50535-mediated tumor growth and metastasis of $\mathrm{CRC}(114,115)$. In addition to $\mathrm{CD}^{+} \mathrm{T}$ cells, how to regulate the Treg cells and Th17 cells in TIME is also a viable option to improve the clinical outcome of cancer therapy.

In recent years, the gut microbiota has received increasing interest as they have been revealed ton interact with many human diseases, including cancer not only limited to colorectal cancer but also extraintestinal tumors (116). The gut microbiota can affect the DNA methylation patterns, chromatin structure, and miRNA activity to maintain the host immune system and homeostasis through the microbes themselves or metabolites (117-119). Butyrate, a short chain fatty acid (SCFA) derived by gut microorganisms, inhibits HDAC activities and induces an abundance of Treg cells, leading to tumor suppression in colitisassociated cancer (CAC), a major subset of CRC $(120,121)$. However, the relationship between HDAC inhibition and Treg cell recruitment in CRC needs to be clarified. Cancer immunotherapy requires microbiota-derived signals because the function of DCs for priming $\mathrm{CD}^{+} \mathrm{T}$ cells is controlled by the gut microbiota through $\mathrm{H} 3 \mathrm{~K} 4 \mathrm{me} 3$, which activates genes related to immune responses $(122,123)$. There is limited evidence illustrating the mechanism of epigenetic modification between gut microbiota and TIME, which makes this area being an interesting field for researchers to investigate.

\section{EPIGENETICS IN INTRATUMORAL HETEROGENEITY}

ITH is termed as subpopulations of cancer cells with different phenotypes and molecular features within a tumor and also contains heterogeneity of the TIME, resulting in tumor metastasis, drug resistance and tumor relapse (Figure 3). Cancer stem cells (CSCs), a small population of stem-like cancer cells within the TIME, are one of the two major frameworks for interpreting the causes of ITH (22). Accumulating evidence suggests that CSCs represent a heterogeneous population of cells that can be regulated by epigenetics, possessing tumorigenicity and metastasis. In breast cancer, the MLL4-mediated H3K4me2 and the $\mathrm{CBP} / \mathrm{p} 300-\mathrm{c}-\mathrm{Myc}$ complex-mediated H3ac contribute to selfrenewal of CSCs by regulating the expression of epithelialmesenchymal transition (EMT) regulators, such as SNAIL, ZEB1, and ZEB2, in the absence of KDM6A (124). KDM6A (also known as UTX), a component of the MLL complex, recruits LSD1, HDAC1, and DNMTs to form a complex that inhibits H3K4me2 and H3ac, and enhances DNA methylation at the promoter regions of SNAIL, ZEB1, and ZEB2, thereby resulting in abolished CSC self-renewal, tumor proliferation, and migration (124). However, the role of KDM6A in breast cancer remains controversy, and whether KDM6A can serve as a therapeutic target needs to be further investigated. The expansion of CSCs is also promoted by TWIST1, whose expression is elevated by the $\mathrm{CBP}$-mediated $\mathrm{H} 3 \mathrm{ac}$ at the promoter, in which CBP degradation is repressed by MTDH, a protein always associated with tumor progression, metastasis, and drug resistance (125). Several epigenetic inhibitors were 


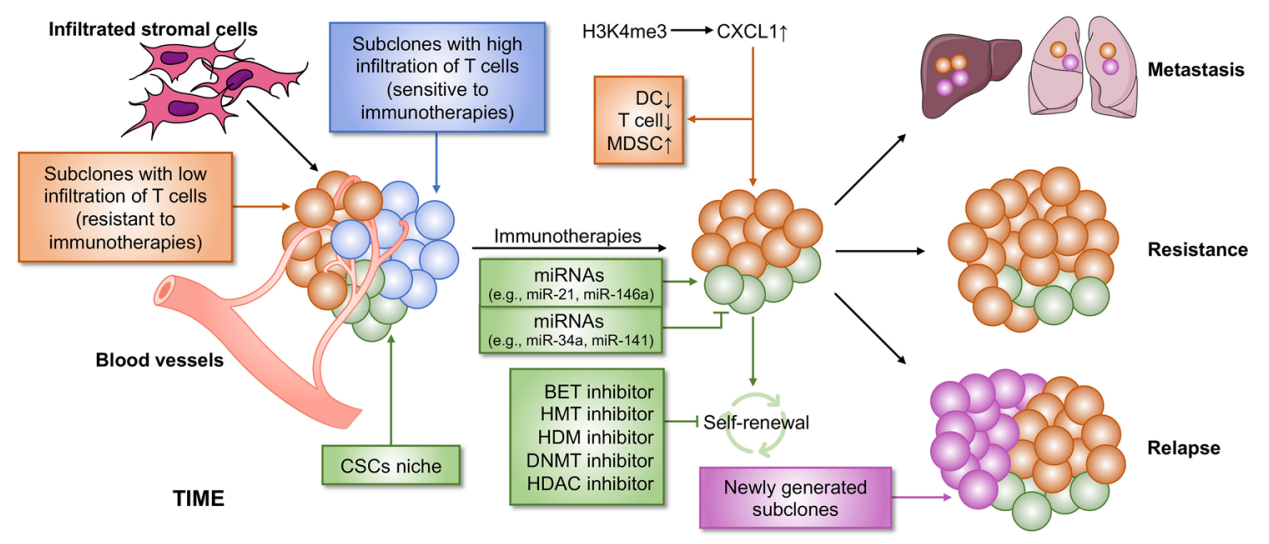

FIGURE 3 | Epigenetic regulation of ITH that contributes to immunotherapy resistance. Cancer is a heterogeneous disease with a complicated TIME, leading to immunotherapy failure. Two main reasons contribute to immunotherapy resistance. First, within the TIME, there are some subpopulations of tumor that are nonresponsive to immunotherapy, which causes resistance to immunotherapy. Second, CSCs cause poor clinical outcome in immunotherapy. CSCs may be not completely eliminated by immunotherapy, which subsequently lead to tumor relapse and metastasis. Both the two processes can be regulated by epigenetics, suggesting that a combination of immunotherapy and epi-drugs may be an effective strategy for cancer therapy. BET, bromodomain and extra-terminal domain; HMT, histone methyltransferase; HDM, histone demethylase; DNMT, DNA methyltransferase; HDAC, histone deacetylase.

investigated to block self-renewal of CSCs, including DNMT, HDAC, histone methyltransferase (HMT), histone demethylase (HDM), and bromodomain and extra-terminal domain (BET) inhibitors $(126,127)$. Additionally, epigenetic regulators, miRNAs, have an ability in modifying CSC development. For example, both miR-34a and miR-141 inhibit prostate cancer stem cells and metastasis by targeting CD44, a CSC marker $(128,129)$.

CSCs are demonstrated to be involved in immune resistance by multiple lines of evidence in many cancer types and therefore contribute to immunosuppressive TIME. One of the main CSC regulators, $\mathrm{c}-\mathrm{Myc}$, that is commonly expressed in many human cancers, can upregulate the expression of immune checkpoint molecules CD47 and PD-L1 (130, 131). Non-autonomously, CSCs from many solid tumors have been proven to be able to release a majority of immunosuppressive factors or cytokines, such as VEGF, TGF- $\beta$, IL-4, IL-6, IL10, PD-1, and others, among which many can help recruit suppressive immune cells, including TAMs, Treg cells, and MDSCs, and impair $\mathrm{CD}^{+} \mathrm{T}$ cell function $(132,133)$. Collectively, CSCs play a pivotal role in the remodeling of TIME to establish an immunosuppressive environment. Multiple therapeutic methods targeting CSCs have sprung up like mushrooms, such as NK cells, CSC-based DC vaccine, CSCbased $\mathrm{T}$ cells (including CAR-T), and monoclonal antibodies (133). Overall, targeting CSC-based immunotherapies is a potential effective strategy for cancer treatment.

Another major framework for interpreting the causes of ITH is clonal evolution (22). The concept clonal evolution was proposed by Nowell in 1976 for the first time (134). Throughout the process of tumor development, clonal evolution preferably proceeds in a branching rather than in a linear manner, and this leads to clonal and (epi)genetic diversity in different subpopulations (22). Cancer therapeutic responses in clinical are largely determined by the evolution of resistant subpopulations and the changes in cellular phenotypes (135).
Moreover, cancer immunotherapy is mainly dependent on the degree of functional infiltrated $\mathrm{T}$ cells, which positively correlates with clinical outcome. However, the number of infiltrated $\mathrm{T}$ cells is discriminated among different subclones originating from a single tumor tissue isolated from a PDA mouse model and associated with epigenetic regulation (108).

First, an autochthonous mouse model, including mutated Kras and p53, of PDA expressing the YFP lineage tag (KPCY) was established. Then, tumor was isolated from KPCY mice and experienced a limiting dilution to generate tumor cell clones. The data showed that TIME is diverse among separated clones, in which low $\mathrm{T}$ cell clones correlated with low DC infiltration and high MDSC recruitment. Tumors formed from clones with low $\mathrm{T}$ cell infiltration negatively correlated with immunotherapeutic responses, demonstrating that ITH could induce tumor relapse in patients responsive to immunotherapy. Mechanistically, CXCL1 was highly expressed in the tumor clones with low $\mathrm{T}$ cell infiltration due to the high levels of $\mathrm{H} 3 \mathrm{~K} 4 \mathrm{me} 3$ enriched at the promoter region of the Cxcll gene. G-CSF, responsible for MDSC recruitment, was also expressed at high levels in the $\mathrm{T}$ cell low tumor clones. However, the exact number of Treg cells was also higher in $\mathrm{T}$ cell high clones than in low clones, suggesting a correlation between Treg cells and immunotherapy response, which needs to be further explored. The inhibition of H3K4me3 might be a potential method for eliminating $\mathrm{T}$ cell low tumor clones and could be combined with immunotherapy to completely eliminate whole tumor in PDA patients.

\section{CLINICAL TRIALS}

The antitumor efficacy of epi-drugs has been proved in preclinical experiments with elevated antitumor immunity. 
Many epi-drugs have been applied to clinical trials, and their ability to eradicate cancer has been investigated. Here, we discuss the recent results of clinical trials involved in epi-drugs (Table 1).

\section{DNMT Inhibitor}

Guadecitabine (SGI-110), a next-generation DNMT inhibitor, is under investigation in clinical trials for its ability of resistance to degradation by cytidine deaminase, leading to a prolonged activity in vivo. It has been confirmed that SGI-110 is able to improve the expression of HLA class I molecule on melanoma cells and the number of CD8+ T cells and CD20+ B cells, which demonstrated that SGI-110 has promising immunomodulatory and antitumor capacity (153).

In a phase I clinical trial for PK/PD analysis, 20 patients with recurrent, platinum-resistant ovarian cancer were enrolled and administered with guadecitabine and carboplatin (136). The first six patients treated with $45 \mathrm{mg} / \mathrm{m}^{2}$ of guadecitabine and carboplatin AUC5 reported neutropenia and thrombocytopenia, while the remaining 14 patients who were treated with $30 \mathrm{mg} / \mathrm{m}^{2}$ of guadecitabine and carboplatin AUC4 reported no such toxicity. Furthermore, three patients had a partial response (PR) and $15 \%$ clinical benefit rate (CBR), and six patients performed stable disease (SD) for more than 3 months with $45 \%$ CBR. Additionally, a CA- 125 reduction of at least $50 \%$ was observed in 5/15 evaluable patients. In summary, this phase I clinical trial demonstrated the efficacy and safety of guadecitabine and carboplatin combination therapy in a platinum-resistant ovarian cancer cohort, supporting a completed Phase II trial (137).

Another phase I trial on guadecitabine was conducted in 22 previously irinotecan-treated patients with metastatic colorectal cancer (mCRC) (138). They were treated across four doses: guadecitabine $30 \mathrm{mg} / \mathrm{m}^{2}$ with or without growth factor support
(GFS) and guadecitabine $45 \mathrm{mg} / \mathrm{m}^{2}$ with or without GFS. Each patient received $125 \mathrm{mg} / \mathrm{m}^{2}$ irinotecan at days 8 and 15 . At the endpoint of this trial, the median overall survival (OS) was 10.7 months, and 17 patients were evaluable, among which, 12 had $\mathrm{SD}$ as the best response and five had PD. Using LINE-1 analysis, global DNA demethylation in tumors was found to be decreased as expected. What's more, guadecitabine $45 \mathrm{mg} / \mathrm{m}^{2}$ and irinotecan $125 \mathrm{mg} / \mathrm{m}^{2}$ with GFS showed the least severe side effects in mCRC patients. These findings provide a theoretical basis for a subsequent randomized phase II trial. In elderly nonfit patients with AML, the combination of retinoic acid and decitabine led to a higher remission rate and increased median overall survival, without additional toxicity (147).

\section{HMT Inhibitor}

Pinometostat (EPZ-5676) is a first-in-class inhibitor of DOT1L, which plays a central role in Th cell lineage commitment and stability, and has been evaluated as a single agent for the treatment of adult patients with advanced acute leukemia, especially those with mixed-lineage leukemia gene rearrangements $(M L L-r)$ leukemia. After treatment, only two patients experienced complete remission at $54 \mathrm{mg} / \mathrm{m}^{2}$ per day, demonstrating the clinical benefit of EPZ-5676 for $M L L-r$ patients (139).

$\mathrm{EZH} 2$ is another attractive target for anti-cancer therapy because of its ability in promoting the division and proliferation of cancerous cells and role in regulating immune cells in TIME, including T cells, NK cells, DCs and macrophages (154). Reprograming the TIME by targeting EZH2 is a viable area of cancer research $(112,155)$. At present, there are three different EZH2 inhibitors, namely tazemetostat, GSK2816126, and CPI-1205, which have been investigated in phase I clinical trials. After treatment with tazemetostat, the most commonly reported adverse event (AE) was asthenia (33\%) in 64 patients

TABLE 1 | Recent clinical trials.

\begin{tabular}{|c|c|c|c|c|c|}
\hline Epigenetic inhibitors & Target & NCT number & Conditions & Status & Reference(s) \\
\hline \multicolumn{6}{|l|}{ DNMT inhibitors } \\
\hline SGl-110 & DNMT1 & NCT01696032 & Ovarian cancer & Phase I & $(136,137)$ \\
\hline SGl-110 & DNMT1 & NCT01896856 & Previously treated metastatic colorectal cancer & Phase $\mid / / I$ & $(138)$ \\
\hline \multicolumn{6}{|l|}{ HMT inhibitors } \\
\hline EPZ-5676 & DOT1L & NCT01684150 & Advanced hematologic malignancies & Phase I & $(139)$ \\
\hline GSK2816126 & $\mathrm{EZH} 2$ & NCT02082977 & Advanced hematological and solid tumors & Phase I & $(140)$ \\
\hline CPI-1205 & $\mathrm{EZH} 2$ & NCT02395601 & B-cell lymphoma & Phase I & $(141)$ \\
\hline Tazemetostat & $\mathrm{EZH} 2$ & NCT01897571 & Advanced solid tumors and B-cell lymphomas & Phase $|/ /|$ & $(142,143)$ \\
\hline \multicolumn{6}{|l|}{ HDAC inhibitors } \\
\hline Panobinostat & pan-HDAC & NCT00878436 & Recurrent prostate cancer after castration & Phase $|/| \mid$ & $(144)$ \\
\hline Vorinostat & pan-HDAC & NCT01422499 & Relapsed solid tumor, lymphoma or leukemia & Phase $1 / \|$ & (145) \\
\hline Vorinostat & pan-HDAC & NCT00731731 & Newly diagnosed glioblastoma multiforme & Phase $|/| \mid$ & $(146)$ \\
\hline \multicolumn{6}{|l|}{ Combinations } \\
\hline $\begin{array}{l}\text { Decitabine/Valproic acid/Retinoic } \\
\text { acid }\end{array}$ & DNMT/HDAC & NCT00867672 & Acute myeloid leukemia & Phase ॥ & $(147)$ \\
\hline Romidepsin/5-azacitidine & HDAC/DNMT & NCT01998035 & Relapsed/refractory lymphoid malignancies & Phase $1 / \|$ & $(148)$ \\
\hline Romidepsin/5-azacitidine & HDAC/DNMT & NCT01537744 & Advanced solid tumors & Phase I & $(149)$ \\
\hline CC-486/pembrolizumab & DNMT/PD-L1 & NCT02546986 & Advanced or metastatic non-small cell lung cancer & Phase II & (150) \\
\hline Vorinostat/pembrolizumab & HDAC/PD-L1 & NCT02638090 & Stage IV non-small cell lung cancer & Phase $1 / \|$ & $(151)$ \\
\hline Vorinostat/pembrolizumab & HDAC/PD-L1 & NCT02538510 & $\begin{array}{l}\text { Recurrent squamous cell head and neck cancer or salivary gland } \\
\text { cancer }\end{array}$ & Phase $1 / I 1$ & $(152)$ \\
\hline
\end{tabular}


(21 with B-cell non-Hodgkin lymphoma and 43 with advanced solid tumors) (142). Among these, no treatment-related deaths occurred, and durable objective response rates were 38 and $5 \%$ in patients with B-cell non-Hodgkin lymphoma and solid tumors, respectively (142). GSK2816126, a highly selective inhibitor of EZH2, was applied for the treatment of 41 patients with solid tumors or B cell lymphoma (140). In this trial, 12 (32\%) patients had a severe $\mathrm{AE}$, and fatigue (53.7\%) and nausea (48.8) were the most common toxicity (140). PK/PD results showed that the half-life of GSK2816126 was approximately $27 \mathrm{~h}$ and its maximum tolerated dose (MTD) was 2,400 mg (140). Finally, $14(34 \%)$ patients experienced the best response of SD and 21 (51\%) patients had progressive disease (140). CPI-1205, the third selective EZH2 inhibitor, was orally administered twice a day in 32 patients with B-cell lymphomas (141). CPI-1205 had the shortest half-life $(\sim 3 \mathrm{~h})$ among the mentioned three EZH2 inhibitors, but induced grade 2 or lower drug-related AEs (141). Among patients, only one achieved a complete response (CR) and five patients had SD (141). Based on these findings, ongoing research needs to be conducted using CPI-1205 in combination in solid tumors (141).

\section{HDAC Inhibitor}

HDAC inhibitors have been proved to be able to alter the secretion level of cytokines and chemokines, favoring a Th1 immune response in cancer therapy (156). Panobinostat, a panHDAC inhibitor, has been approved by FDA for use in multiple myeloma patients in 2015 and able to improve NK cell-mediated tumor eradication $(156,157)$. In a phase I/II clinical trial, panobinostat was combined with bicalutamide to treat patients with castration-resistant prostate cancer (CRPC) and restore the resistance to bicalutamide in CRPC patients $(n=64$; Phase I: 9; Phase II: 55) (144). In the phase II trial, panobinostat at $40 \mathrm{mg}$ p.o. triweekly was selected as the highest oral dose based on the Phase I trial (144). The median time to PSA progression was 9.4 and 6.3 weeks for the A and B arms, respectively (144). The most common AE for the two arms was fatigue (55 and 65\%, respectively), and the toxicity of panobinostat was tolerable with dose reductions (144). Overall, panobinostat, together with bicalutamide, increased rPFS in CRPC patients and reduced androgen receptor-mediated resistance to bicalutamide (144).

HDAC inhibitors can also be combined with DNMT inhibitors for the treatment of lymphomas, AML, and solid tumors. In a phase I study, 5-azacytidine (a DNMT inhibitor) and romidepsin (a HDAC inhibitor) were combined for the treatment of patients with peripheral T-cell lymphoma (PTCL) (148). This combination therapy was well-tolerated in lymphoid malignancy patients and produced a better overall response rate (73\%) and complete response rate (55\%) in patients with PTCL than in those with non-T-cell lymphoma (148). Combined with the DNMT inhibitor CC-486, romidepsin was investigated in another phase I clinical trial, in which 18 patients with advanced solid tumors were enrolled (149). Although the combination of CC-486 and romidepsin was tolerable, the antitumor effect was not significant (149). Another HDAC inhibitor vorinostat was investigated in two Phase I/II clinical trials as a single agent or in combination therapy $(145,146)$.

\section{Combination Therapy With ICI}

Most patients exhibited no or partial response to ICI therapy, which is attributed to several factors, including tumor mutational burden (TMB), TIME and tumor immune evasion (9). Owing to the function of epigenetic regulation in malignancies, the combination of epi-drugs and ICI therapy may be open a new gate for cancer therapy, especially DNMT inhibitor and HDAC inhibitor (158).

A randomized phase II study was conducted to compare the treatment efficacy and safety of pembrolizumab (PD-L1 monoantibody) plus CC-486 or placebo in NSCLC patients previously treated with platinum (150). Unfortunately, no improved PFS was shown between pembrolizumab + CC-486 and pembrolizumab + placebo arms. The treatment feasibility might be influenced by AEs, particularly gastrointestinal, thus resulting in non-comparable median OS (11.9 months vs. not estimable) (150).

Two clinical trials, a phase I/Ib and a Phase II, were performed using pembrolizumab and vorinostat combination therapy in patients with NSCLC, and head and neck (HN) and salivary gland cancer (SGC), respectively. The phase I/Ib study demonstrated that pembrolizumab (200 $\mathrm{mg}$ ) plus vorinostat $(400$ $\mathrm{mg}$ ) were the recommended dose which was well tolerated (151). Among the enrolled 33 patients, 30 were evaluable for response: four (13\%) had partial response; 16 (53\%) had SD; and $10(33 \%)$ had progressive disease (151). In the ICI-pretreated cohort, $\mathrm{CD}^{+} \mathrm{T}$ cell presence in the tumor stromal area was correlated with treatment benefit (151). While MDSCs showed no such association. Another combination therapy involving pembrolizumab and vorinostat was investigated in a phase II trial conducted in $25 \mathrm{HN}$ and 25 SGC patients (152). The toxicities of this combination therapy were more severe than those of pembrolizumab alone reported elsewhere. The median OS and median PFS were 12.6 and 4.5 months and 14 and 6.9 months in the HN and SGC cohorts, respectively. Beneficial responses in SGC were reportedly fewer than those in $\mathrm{HN}$ when treated with pembrolizumab and vorinostat, possibly due to the low expression of PD-L1 on SGC.

\section{CONCLUSION}

Epigenetic regulation (DNA methylation, histone modification, and ncRNAs) plays a controversial role in cancer initiation and progression, especially in the modification of TIME. Epigeneticsrelated drugs approved by FDA are proved to be sufficient for cancer therapy, suggesting that targeting epigenetic pathway is a promising strategy for cancer treatment. This strategy can not only induce anti-proliferation of tumor cells, but also shift the TIME from cold to hot. Moreover, the gut microbiota-mediated epigenetic regulation can also influence tumor cells and the host immune system; however, the mechanism by which the microbiota epigenetically shape TIME needs to be further 
investigated. Another interesting area of research is the epigenetic regulation of B cell function in tumor development. Because of ITH, therapies targeting each tumor clone and CSCs represent new directions for cancer treatment.

Both pre-clinical and clinical studies have confirmed the antitumor effect of epi-drugs. However, a single epi-drug had not achieved much positive feedback in clinical trials, demonstrating that epi-drugs should be employed in combination with other cancer therapeutic approaches, including chemotherapy, radiotherapy, and immunotherapy, particularly ICI therapy. Due to the toxicity of epi-drugs, ongoing research should focus on how to decrease their side effects. ncRNAs are well-known group of factors that regulate tumor development. Thus, combination of ncRNA-related drugs and immunotherapy may be another potential strategy for cancer treatment in clinical trials.

\section{REFERENCES}

1. Feng RM, Zong YN, Cao SM, Xu RH. Current cancer situation in China: good or bad news from the 2018 Global Cancer Statistics? Cancer Commun (Lond) (2019) 39(1):22. doi: 10.1186/s40880-019-0368-6

2. Bray F, Ferlay J, Soerjomataram I, Siegel RL, Torre LA, Jemal A. Global cancer statistics 2018: GLOBOCAN estimates of incidence and mortality worldwide for 36 cancers in 185 countries. CA Cancer J Clin (2018) 68 (6):394-424. doi: 10.3322/caac. 21492

3. Siegel RL, Miller KD, Jemal A. Cancer statistics, 2019. CA Cancer J Clin (2019) 69(1):7-34. doi: 10.3322/caac.21551

4. Boedtkjer E, Pedersen SF. The Acidic Tumor Microenvironment as a Driver of Cancer. Annu Rev Physiol (2020) 82:103-26. doi: 10.1146/annurevphysiol-021119-034627

5. Binnewies M, Roberts EW, Kersten K, Chan V, Fearon DF, Merad M, et al. Understanding the tumor immune microenvironment (TIME) for effective therapy. Nat Med (2018) 24(5):541-50. doi: 10.1038/s41591-018-0014-x

6. Topalian SL, Drake CG, Pardoll DM. Immune checkpoint blockade: a common denominator approach to cancer therapy. Cancer Cell (2015) 27 (4):450-61. doi: 10.1016/j.ccell.2015.03.001

7. Easwaran H, Tsai HC, Baylin SB. Cancer epigenetics: tumor heterogeneity, plasticity of stem-like states, and drug resistance. Mol Cell (2014) 54(5):71627. doi: 10.1016/j.molcel.2014.05.015

8. Saleh R, Toor SM, Sasidharan Nair V, Elkord E. Role of Epigenetic Modifications in Inhibitory Immune Checkpoints in Cancer Development and Progression. Front Immunol (2020) 11:1469. doi: 10.3389/fimmu. 2020.01469

9. Topper MJ, Vaz M, Marrone KA, Brahmer JR, Baylin SB. The emerging role of epigenetic therapeutics in immuno-oncology. Nat Rev Clin Oncol (2020) 17(2):75-90. doi: 10.1038/s41571-019-0266-5

10. Shih HY, Sciumè G, Poholek AC, Vahedi G, Hirahara K, Villarino AV, et al. Transcriptional and epigenetic networks of helper $\mathrm{T}$ and innate lymphoid cells. Immunol Rev (2014) 261(1):23-49. doi: 10.1111/imr.12208

11. Tripathi SK, Lahesmaa R. Transcriptional and epigenetic regulation of Thelper lineage specification. Immunol Rev (2014) 261(1):62-83. doi: 10.1111/ imr.12204

12. Youngblood B, Hale JS, Kissick HT, Ahn E, Xu X, Wieland A, et al. Effector CD8 T cells dedifferentiate into long-lived memory cells. Nature (2017) 552 (7685):404-9. doi: 10.1038/nature25144

13. Zheng H, Zhao W, Yan C, Watson CC, Massengill M, Xie M, et al. HDAC Inhibitors Enhance T-Cell Chemokine Expression and Augment Response to PD-1 Immunotherapy in Lung Adenocarcinoma. Clin Cancer Res (2016) 22(16):4119-32. doi: 10.1158/1078-0432.Ccr-15-2584

14. Youngblood B, Oestreich KJ, Ha SJ, Duraiswamy J, Akondy RS, West EE, et al. Chronic virus infection enforces demethylation of the locus that encodes PD-1 in antigen-specific CD8(+) T cells. Immunity (2011) 35 (3):400-12. doi: 10.1016/j.immuni.2011.06.015

\section{AUTHOR CONTRIBUTIONS}

YY and YW wrote the manuscript. YW critically revised the manuscript. All authors contributed to the article and approved the submitted version.

\section{FUNDING}

This work was supported by the National Natural Science Foundation of China (No. 41931291, No. 81773017 to YW), the Chinese Academy of Medical Science Innovation Fund for Medical Sciences (CIFMS; No. 2019-I2M-1-003), and the Nonprofit Central Research Institute Fund of Chinese Academy of Medical Sciences (2019PT310027).

15. Stone ML, Chiappinelli KB, Li H, Murphy LM, Travers ME, Topper MJ, et al. Epigenetic therapy activates type I interferon signaling in murine ovarian cancer to reduce immunosuppression and tumor burden. Proc Natl Acad Sci U S A (2017) 114(51):E10981-90. doi: 10.1073/pnas.1712514114

16. Topper MJ, Vaz M, Chiappinelli KB, DeStefano Shields CE, Niknafs N, Yen RC, et al. Epigenetic Therapy Ties MYC Depletion to Reversing Immune Evasion and Treating Lung Cancer. Cell (2017) 171(6):1284-300.e21. doi: 10.1016/j.cell.2017.10.022

17. Chiappinelli KB, Strissel PL, Desrichard A, Li H, Henke C, Akman B, et al. Inhibiting DNA Methylation Causes an Interferon Response in Cancer via dsRNA Including Endogenous Retroviruses. Cell (2015) 162(5):974-86. doi: 10.1016/j.cell.2015.07.011

18. Li H, Chiappinelli KB, Guzzetta AA, Easwaran H, Yen RW, Vatapalli R, et al. Immune regulation by low doses of the DNA methyltransferase inhibitor 5 azacitidine in common human epithelial cancers. Oncotarget (2014) 5 (3):587-98. doi: 10.18632/oncotarget.1782

19. Roulois D, Loo Yau H, Singhania R, Wang Y, Danesh A, Shen SY, et al. DNA-Demethylating Agents Target Colorectal Cancer Cells by Inducing Viral Mimicry by Endogenous Transcripts. Cell (2015) 162(5):961-73. doi: 10.1016/j.cell.2015.07.056

20. Goodyear O, Agathanggelou A, Novitzky-Basso I, Siddique S, McSkeane T, Ryan G, et al. Induction of a CD8+ T-cell response to the MAGE cancer testis antigen by combined treatment with azacitidine and sodium valproate in patients with acute myeloid leukemia and myelodysplasia. Blood (2010) 116(11):1908-18. doi: 10.1182/blood-2009-11-249474

21. Natsume A, Wakabayashi T, Tsujimura K, Shimato S, Ito M, Kuzushima K, et al. The DNA demethylating agent 5-aza-2'-deoxycytidine activates NYESO-1 antigenicity in orthotopic human glioma. Int J Cancer (2008) 122 (11):2542-53. doi: 10.1002/ijc.23407

22. Marusyk A, Almendro V, Polyak K. Intra-tumour heterogeneity: a looking glass for cancer? Nat Rev Cancer (2012) 12(5):323-34. doi: 10.1038/nrc3261

23. Kim C, Gao R, Sei E, Brandt R, Hartman J, Hatschek T, et al. Chemoresistance Evolution in Triple-Negative Breast Cancer Delineated by Single-Cell Sequencing. Cell (2018) 173(4):879-93.e13. doi: 10.1016/j.cell.2018.03.041

24. Guo M, Peng Y, Gao A, Du C, Herman JG. Epigenetic heterogeneity in cancer. Biomark Res (2019) 7:23. doi: 10.1186/s40364-019-0174-y

25. Wu TP, Wang T, Seetin MG, Lai Y, Zhu S, Lin K, et al. DNA methylation on $\mathrm{N}(6)$-adenine in mammalian embryonic stem cells. Nature (2016) 532 (7599):329-33. doi: 10.1038/nature17640

26. Jasiulionis MG. Abnormal Epigenetic Regulation of Immune System during Aging. Front Immunol (2018) 9:197. doi: 10.3389/fimmu.2018.00197

27. Villanueva L, Álvarez-Errico D, Esteller M. The Contribution of Epigenetics to Cancer Immunotherapy. Trends Immunol (2020) 41(8):676-91. doi: 10.1016/j.it.2020.06.002

28. Okano M, Bell DW, Haber DA, Li E. DNA methyltransferases Dnmt3a and Dnmt3b are essential for de novo methylation and mammalian development. Cell (1999) 99(3):247-57. doi: 10.1016/s0092-8674(00)81656-6 
29. Hermann A, Goyal R, Jeltsch A. The Dnmt1 DNA-(cytosine-C5)methyltransferase methylates DNA processively with high preference for hemimethylated target sites. J Biol Chem (2004) 279(46):48350-9. doi: $10.1074 /$ jbc.M403427200

30. Goll MG, Kirpekar F, Maggert KA, Yoder JA, Hsieh CL, Zhang X, et al. Methylation of tRNAAsp by the DNA methyltransferase homolog Dnmt2. Science (2006) 311(5759):395-8. doi: 10.1126/science.1120976

31. Jones PA. Functions of DNA methylation: islands, start sites, gene bodies and beyond. Nat Rev Genet (2012) 13(7):484-92. doi: 10.1038/nrg3230

32. Maunakea AK, Nagarajan RP, Bilenky M, Ballinger TJ, D'Souza C, Fouse SD, et al. Conserved role of intragenic DNA methylation in regulating alternative promoters. Nature (2010) 466(7303):253-7. doi: 10.1038/nature09165

33. Tahiliani M, Koh KP, Shen Y, Pastor WA, Bandukwala H, Brudno Y, et al. Conversion of 5-methylcytosine to 5-hydroxymethylcytosine in mammalian DNA by MLL partner TET1. Science (2009) 324(5929):930-5. doi: 10.1126/ science.1170116

34. Ito S, Shen L, Dai Q, Wu SC, Collins LB, Swenberg JA, et al. Tet proteins can convert 5-methylcytosine to 5-formylcytosine and 5-carboxylcytosine. Science (2011) 333(6047):1300-3. doi: 10.1126/science.1210597

35. Robertson KD. DNA methylation, methyltransferases, and cancer. Oncogene (2001) 20(24):3139-55. doi: 10.1038/sj.onc.1204341

36. Elashi AA, Sasidharan Nair V, Taha RZ, Shaath H, Elkord E. DNA methylation of immune checkpoints in the peripheral blood of breast and colorectal cancer patients. Oncoimmunology (2019) 8(2):e1542918. doi: 10.1080/2162402x.2018.1542918

37. Jung H, Kim HS, Kim JY, Sun JM, Ahn JS, Ahn MJ, et al. DNA methylation loss promotes immune evasion of tumours with high mutation and copy number load. Nat Commun (2019) 10(1):4278. doi: 10.1038/s41467-019-12159-9

38. Schuyler RP, Merkel A, Raineri E, Altucci L, Vellenga E, Martens JHA, et al. Distinct Trends of DNA Methylation Patterning in the Innate and Adaptive Immune Systems. Cell Rep (2016) 17(8):2101-11. doi: 10.1016/ j.celrep.2016.10.054

39. Zhao Z, Shilatifard A. Epigenetic modifications of histones in cancer. Genome Biol (2019) 20(1):245. doi: 10.1186/s13059-019-1870-5

40. Bannister AJ, Kouzarides T. Regulation of chromatin by histone modifications. Cell Res (2011) 21(3):381-95. doi: 10.1038/cr.2011.22

41. Chan JC, Maze I. Nothing Is Yet Set in (Hi)stone: Novel Post-Translational Modifications Regulating Chromatin Function. Trends Biochem Sci (2020) 45(10):829-44. doi: 10.1016/j.tibs.2020.05.009

42. Mohan M, Herz HM, Shilatifard A. SnapShot: Histone lysine methylase complexes. Cell (2012) 149(2):498-498.e1. doi: 10.1016/j.cell.2012.03.025

43. Herz HM, Garruss A, Shilatifard A. SET for life: biochemical activities and biological functions of SET domain-containing proteins. Trends Biochem Sci (2013) 38(12):621-39. doi: 10.1016/j.tibs.2013.09.004

44. Araki Y, Wang Z, Zang C, Wood WH3, Schones D, Cui K, et al. Genomewide analysis of histone methylation reveals chromatin state-based regulation of gene transcription and function of memory CD8+ T cells. Immunity (2009) 30(6):912-25. doi: 10.1016/j.immuni.2009.05.006

45. Bian Y, Li W, Kremer DM, Sajjakulnukit P, Li S, Crespo J, et al. Cancer SLC43A2 alters $\mathrm{T}$ cell methionine metabolism and histone methylation. Nature (2020) 585(7824):277-82. doi: 10.1038/s41586-020-2682-1

46. Tan AHY, Tu W, McCuaig R, Hardy K, Donovan T, Tsimbalyuk S, et al. Lysine-Specific Histone Demethylase 1A Regulates Macrophage Polarization and Checkpoint Molecules in the Tumor Microenvironment of TripleNegative Breast Cancer. Front Immunol (2019) 10:1351. doi: 10.3389/ fimmu.2019.01351

47. Zhou Z, Chen H, Xie R, Wang H, Li S, Xu Q, et al. Epigenetically modulated FOXM1 suppresses dendritic cell maturation in pancreatic cancer and colon cancer. Mol Oncol (2019) 13(4):873-93. doi: 10.1002/1878-0261.12443

48. Yin J, Leavenworth JW, Li Y, Luo Q, Xie H, Liu X, et al. Ezh2 regulates differentiation and function of natural killer cells through histone methyltransferase activity. Proc Natl Acad Sci U S A (2015) 112 (52):15988-93. doi: 10.1073/pnas.1521740112

49. Choudhary C, Kumar C, Gnad F, Nielsen ML, Rehman M, Walther TC, et al. Lysine acetylation targets protein complexes and co-regulates major cellular functions. Science (2009) 325(5942):834-40. doi: 10.1126/science.1175371

50. Kouzarides T. Chromatin modifications and their function. Cell (2007) 128 (4):693-705. doi: 10.1016/j.cell.2007.02.005
51. Ellmeier W, Seiser C. Histone deacetylase function in CD4(+) T cells. Nat Rev Immunol (2018) 18(10):617-34. doi: 10.1038/s41577-018-0037-z

52. Parthun MR. Hat1: the emerging cellular roles of a type $B$ histone acetyltransferase. Oncogene (2007) 26(37):5319-28. doi: 10.1038/ sj.onc. 1210602

53. Marmorstein R, Zhou MM. Writers and readers of histone acetylation: structure, mechanism, and inhibition. Cold Spring Harb Perspect Biol (2014) 6(7):a018762. doi: 10.1101/cshperspect.a018762

54. Zhan X, Guo S, Li Y, Ran H, Huang H, Mi L, et al. Glioma stem-like cells evade interferon suppression through $\mathrm{MBD} / \mathrm{NuRD}$ complex-mediated STAT1 downregulation. J Exp Med (2020) 217(5):1-18. doi: 10.1084/ jem.20191340

55. Jones PA, Issa JP, Baylin S. Targeting the cancer epigenome for therapy. Nat Rev Genet (2016) 17(10):630-41. doi: 10.1038/nrg.2016.93

56. Woods DM, Sodré AL, Villagra A, Sarnaik A, Sotomayor EM, Weber J. HDAC Inhibition Upregulates PD-1 Ligands in Melanoma and Augments Immunotherapy with PD-1 Blockade. Cancer Immunol Res (2015) 3 (12):1375-85. doi: 10.1158/2326-6066.Cir-15-0077-t

57. Cruickshank B, Giacomantonio M, Marcato P, McFarland S, Pol J, Gujar S. Dying to Be Noticed: Epigenetic Regulation of Immunogenic Cell Death for Cancer Immunotherapy. Front Immunol (2018) 9:654. doi: 10.3389/fimmu. 2018.00654

58. Koh A, De Vadder F, Kovatcheva-Datchary P, Bäckhed F. From Dietary Fiber to Host Physiology: Short-Chain Fatty Acids as Key Bacterial Metabolites. Cell (2016) 165(6):1332-45. doi: 10.1016/j.cell.2016.05.041

59. Rossetto D, Truman AW, Kron SJ, Côté J. Epigenetic modifications in double-strand break DNA damage signaling and repair. Clin Cancer Res (2010) 16(18):4543-52. doi: 10.1158/1078-0432.Ccr-10-0513

60. Surapaneni SK, Bhat ZR, Tikoo K. MicroRNA-941 regulates the proliferation of breast cancer cells by altering histone H3 Ser 10 phosphorylation. Sci Rep (2020) 10(1):17954. doi: 10.1038/s41598-02074847-7

61. Liu Y, Long YH, Wang SQ, Zhang YY, Li YF, Mi JS, et al. JMJD6 regulates histone H2A.X phosphorylation and promotes autophagy in triple-negative breast cancer cells via a novel tyrosine kinase activity. Oncogene (2019) 38 (7):980-97. doi: 10.1038/s41388-018-0466-y

62. Mahajan K, Malla P, Lawrence HR, Chen Z, Kumar-Sinha C, Malik R, et al. ACK1/TNK2 Regulates Histone H4 Tyr88-phosphorylation and AR Gene Expression in Castration-Resistant Prostate Cancer. Cancer Cell (2017) 31 (6):790-803.e8. doi: 10.1016/j.ccell.2017.05.003

63. Hua JT, Chen S, He HH. Landscape of Noncoding RNA in Prostate Cancer. Trends Genet (2019) 35(11):840-51. doi: 10.1016/j.tig.2019.08.004

64. Fabian MR, Sonenberg N, Filipowicz W. Regulation of mRNA translation and stability by microRNAs. Annu Rev Biochem (2010) 79:351-79. doi: 10.1146/annurev-biochem-060308-103103

65. Otto T, Candido SV, Pilarz MS, Sicinska E, Bronson RT, Bowden M, et al. Cell cycle-targeting microRNAs promote differentiation by enforcing cellcycle exit. Proc Natl Acad Sci U S A (2017) 114(40):10660-5. doi: 10.1073/ pnas. 1702914114

66. Balaga O, Friedman Y, Linial M. Toward a combinatorial nature of microRNA regulation in human cells. Nucleic Acids Res (2012) 40 (19):9404-16. doi: 10.1093/nar/gks759

67. Di Leva G, Garofalo M, Croce CM. MicroRNAs in cancer. Annu Rev Pathol (2014) 9:287-314. doi: 10.1146/annurev-pathol-012513-104715

68. Wei J, Nduom EK, Kong LY, Hashimoto Y, Xu S, Gabrusiewicz K, et al. MiR138 exerts anti-glioma efficacy by targeting immune checkpoints. Neuro Oncol (2016) 18(5):639-48. doi: 10.1093/neuonc/nov292

69. Liu WL, Wang HX, Shi CX, Shi FY, Zhao LY, Zhao W, et al. MicroRNA1269 promotes cell proliferation via the AKT signaling pathway by targeting RASSF9 in human gastric cancer. Cancer Cell Int (2019) 19:308. doi: 10.1186/s12935-019-1026-4

70. Chen X, Yang F, Zhang T, Wang W, Xi W, Li Y, et al. MiR-9 promotes tumorigenesis and angiogenesis and is activated by MYC and OCT4 in human glioma. J Exp Clin Cancer Res (2019) 38(1):99. doi: 10.1186/s13046019-1078-2

71. Eichmüller SB, Osen W, Mandelboim O, Seliger B. Immune Modulatory microRNAs Involved in Tumor Attack and Tumor Immune Escape. J Natl Cancer Inst (2017) 109(10):1-14. doi: 10.1093/jnci/djx034 
72. Zhang Y, Li X, Zhang J, Liang H. Natural killer T cell cytotoxic activity in cervical cancer is facilitated by the LINC00240/microRNA-124-3p/STAT3/ MICA axis. Cancer Lett (2020) 474:63-73. doi: 10.1016/j.canlet.2019.12.038

73. Hu Q, Ye Y, Chan LC, Li Y, Liang K, Lin A, et al. Oncogenic IncRNA downregulates cancer cell antigen presentation and intrinsic tumor suppression. Nat Immunol (2019) 20(7):835-51. doi: 10.1038/s41590-019-0400-7

74. Yuan JH, Yang F, Wang F, Ma JZ, Guo YJ, Tao QF, et al. A long noncoding RNA activated by TGF- $\beta$ promotes the invasion-metastasis cascade in hepatocellular carcinoma. Cancer Cell (2014) 25(5):666-81. doi: 10.1016/ j.ccr.2014.03.010

75. Jiang R, Tang J, Chen Y, Deng L, Ji J, Xie Y, et al. The long noncoding RNA lnc-EGFR stimulates T-regulatory cells differentiation thus promoting hepatocellular carcinoma immune evasion. Nat Commun (2017) 8:15129. doi: $10.1038 /$ ncomms 15129

76. Chen C, He W, Huang J, Wang B, Li H, Cai Q, et al. LNMAT1 promotes lymphatic metastasis of bladder cancer via CCL2 dependent macrophage recruitment. Nat Commun (2018) 9(1):3826. doi: 10.1038/s41467-01806152-x

77. Huang D, Chen J, Yang L, Ouyang Q, Li J, Lao L, et al. NKILA lncRNA promotes tumor immune evasion by sensitizing $\mathrm{T}$ cells to activation-induced cell death. Nat Immunol (2018) 19(10):1112-25. doi: 10.1038/s41590-0180207-y

78. Sang LJ, Ju HQ, Liu GP, Tian T, Ma GL, Lu YX, et al. LncRNA CamK-A Regulates $\mathrm{Ca}(2+)$-Signaling-Mediated Tumor Microenvironment Remodeling. Mol Cell (2018) 72(3):601. doi: 10.1016/j.molcel.2018.10.024

79. Network, T.C.G.A.R. Comprehensive and Integrated Genomic Characterization of Adult Soft Tissue Sarcomas. Cell (2017) 171(4):95065.e28. doi: 10.1016/j.cell.2017.10.014

80. Hou P, Kapoor A, Zhang Q, Li J, Wu CJ, Li J, et al. Tumor Microenvironment Remodeling Enables Bypass of Oncogenic KRAS Dependency in Pancreatic Cancer. Cancer Discov (2020) 10(7):1058-77. doi: 10.1158/2159-8290.Cd-19-0597

81. Zhang Y, Yang P, Sun T, Li D, Xu X, Rui Y, et al. miR-126 and miR-126* repress recruitment of mesenchymal stem cells and inflammatory monocytes to inhibit breast cancer metastasis. Nat Cell Biol (2013) 15 (3):284-94. doi: 10.1038/ncb2690

82. Chang YC, Chen TC, Lee CT, Yang CY, Wang HW, Wang CC, et al. Epigenetic control of MHC class II expression in tumor-associated macrophages by decoy receptor 3. Blood (2008) 111(10):5054-63. doi: 10.1182/blood-2007-12-130609

83. Kim HJ, Cantor H, Cosmopoulos K. Overcoming Immune Checkpoint Blockade Resistance via EZH2 Inhibition. Trends Immunol (2020) 41 (10):948-63. doi: 10.1016/j.it.2020.08.010

84. Safarzadeh E, Hashemzadeh S, Duijf PHG, Mansoori B, Khaze V, Mohammadi A, et al. Circulating myeloid-derived suppressor cells: An independent prognostic factor in patients with breast cancer. J Cell Physiol (2019) 234(4):3515-25. doi: 10.1002/jcp.26896

85. Zhou J, Liu M, Sun H, Feng Y, Xu L, Chan AWH, et al. Hepatoma-intrinsic CCRK inhibition diminishes myeloid-derived suppressor cell immunosuppression and enhances immune-checkpoint blockade efficacy. Gut (2018) 67(5):931-44. doi: 10.1136/gutjnl-2017-314032

86. Welte T, Kim IS, Tian L, Gao X, Wang H, Li J, et al. Oncogenic mTOR signalling recruits myeloid-derived suppressor cells to promote tumour initiation. Nat Cell Biol (2016) 18(6):632-44. doi: 10.1038/ncb3355

87. Feng H, Yu Z, Tian Y, Lee YY, Li MS, Go MY, et al. A CCRK-EZH2 epigenetic circuitry drives hepatocarcinogenesis and associates with tumor recurrence and poor survival of patients. J Hepatol (2015) 62(5):1100-11. doi: 10.1016/j.jhep.2014.11.040

88. Bella L, Zona S, Nestal de Moraes G, Lam EW. FOXM1: A key oncofoetal transcription factor in health and disease. Semin Cancer Biol (2014) 29:32-9. doi: 10.1016/j.semcancer.2014.07.008

89. Zhang B, Wu Q, Li B, Wang D, Wang L, Zhou YL. m(6)A regulatormediated methylation modification patterns and tumor microenvironment infiltration characterization in gastric cancer. Mol Cancer (2020) 19(1):53. doi: 10.1186/s12943-020-01170-0

90. Wang H, Hu X, Huang M, Liu J, Gu Y, Ma L, et al. Mettl3-mediated mRNA m(6)A methylation promotes dendritic cell activation. Nat Commun (2019) 10(1):1898. doi: 10.1038/s41467-019-09903-6
91. Han D, Liu J, Chen C, Dong L, Liu Y, Chang R, et al. Anti-tumour immunity controlled through mRNA m(6)A methylation and YTHDF1 in dendritic cells. Nature (2019) 566(7743):270-4. doi: 10.1038/s41586-019-0916-x

92. Chen P, Hsu WH, Chang A, Tan Z, Lan Z, Zhou A, et al. Circadian Regulator CLOCK Recruits Immune-Suppressive Microglia into the GBM Tumor Microenvironment. Cancer Discov (2020) 10(3):371-81. doi: 10.1158/21598290.Cd-19-0400

93. Figueroa ME, Abdel-Wahab O, Lu C, Ward PS, Patel J, Shih A, et al. Leukemic IDH1 and IDH2 mutations result in a hypermethylation phenotype, disrupt TET2 function, and impair hematopoietic differentiation. Cancer Cell (2010) 18(6):553-67. doi: 10.1016/ j.ccr.2010.11.015

94. Lemke D, Pfenning PN, Sahm F, Klein AC, Kempf T, Warnken U, et al. Costimulatory protein $4 \mathrm{IgB} 7 \mathrm{H} 3$ drives the malignant phenotype of glioblastoma by mediating immune escape and invasiveness. Clin Cancer Res (2012) 18(1):105-17. doi: 10.1158/1078-0432.Ccr-11-0880

95. Xu H, Cheung IY, Guo HF, Cheung NK. MicroRNA miR-29 modulates expression of immunoinhibitory molecule B7-H3: potential implications for immune based therapy of human solid tumors. Cancer Res (2009) 69 (15):6275-81. doi: 10.1158/0008-5472.Can-08-4517

96. Rusek AM, Abba M, Eljaszewicz A, Moniuszko M, Niklinski J, Allgayer H. MicroRNA modulators of epigenetic regulation, the tumor microenvironment and the immune system in lung cancer. Mol Cancer (2015) 14:34. doi: 10.1186/s12943-015-0302-8

97. Kim TD, Lee SU, Yun S, Sun HN, Lee SH, Kim JW, et al. Human microRNA$27 a^{*}$ targets Prf1 and GzmB expression to regulate NK-cell cytotoxicity. Blood (2011) 118(20):5476-86. doi: 10.1182/blood-2011-04-347526

98. Yun S, Lee SU, Kim JM, Lee HJ, Song HY, Kim YK, et al. Integrated mRNAmicroRNA profiling of human NK cell differentiation identifies MiR-583 as a negative regulator of IL2R $\gamma$ expression. PloS One (2014) 9(10):e108913. doi: 10.1371/journal.pone.0108913

99. Regis S, Caliendo F, Dondero A, Casu B, Romano F, Loiacono F, et al. TGF$\beta 1$ Downregulates the Expression of CX(3)CR1 by Inducing miR-27a-5p in Primary Human NK Cells. Front Immunol (2017) 8:868. doi: 10.3389/fimmu. 2017.00868

100. Donatelli SS, Zhou JM, Gilvary DL, Eksioglu EA, Chen X, Cress WD, et al. TGF- $\beta$-inducible microRNA-183 silences tumor-associated natural killer cells. Proc Natl Acad Sci U S A (2014) 111(11):4203-8. doi: 10.1073/ pnas. 1319269111

101. Burr ML, Sparbier CE, Chan KL, Chan YC, Kersbergen A, Lam EYN, et al. An Evolutionarily Conserved Function of Polycomb Silences the MHC Class I Antigen Presentation Pathway and Enables Immune Evasion in Cancer. Cancer Cell (2019) 36(4):385-401.e8. doi: 10.1016/j.ccell.2019.08.008

102. Li J, Yuan S, Norgard RJ, Yan F, Sun YH, Kim IK, et al. Epigenetic and transcriptional control of the epidermal growth factor receptor (EGFR) regulates the tumor immune microenvironment in pancreatic cancer. Cancer Discov (2020) 11(3):736-53. doi: 10.1158/2159-8290.Cd-20-0519

103. Galluzzi L, Chan TA, Kroemer G, Wolchok JD, López-Soto A. The hallmarks of successful anticancer immunotherapy. Sci Transl Med (2018) 10(459):114. doi: $10.1126 /$ scitranslmed.aat7807

104. Toor SM, Sasidharan Nair V, Decock J, Elkord E. Immune checkpoints in the tumor microenvironment. Semin Cancer Biol (2020) 65:1-12. doi: 10.1016/ j.semcancer.2019.06.021

105. Berglund A, Mills M, Putney RM, Hamaidi I, Mulé J, Kim S. Methylation of immune synapse genes modulates tumor immunogenicity. J Clin Invest (2020) 130(2):974-80. doi: 10.1172/jci131234

106. Mok MT, Zhou J, Tang W, Zeng X, Oliver AW, Ward SE, et al. CCRK is a novel signalling hub exploitable in cancer immunotherapy. Pharmacol Ther (2018) 186:138-51. doi: 10.1016/j.pharmthera.2018.01.008

107. Spranger S, Bao R, Gajewski TF. Melanoma-intrinsic $\beta$-catenin signalling prevents anti-tumour immunity. Nature (2015) 523(7559):231-5. doi: 10.1038/nature14404

108. Li J, Byrne KT, Yan F, Yamazoe T, Chen Z, Baslan T, et al. Tumor CellIntrinsic Factors Underlie Heterogeneity of Immune Cell Infiltration and Response to Immunotherapy. Immunity (2018) 49(1):178-93.e7. doi: 10.1016/ j.immuni.2018.06.006

109. Peng D, Kryczek I, Nagarsheth N, Zhao L, Wei S, Wang W, et al. Epigenetic silencing of TH1-type chemokines shapes tumour immunity and 
immunotherapy. Nature (2015) 527(7577):249-53. doi: 10.1038/ nature 15520

110. Liu X, Wang Y, Lu H, Li J, Yan X, Xiao M, et al. Genome-wide analysis identifies NR4A1 as a key mediator of T cell dysfunction. Nature (2019) 567 (7749):525-9. doi: 10.1038/s41586-019-0979-8

111. Yang P, Li QJ, Feng Y, Zhang Y, Markowitz GJ, Ning S, et al. TGF- $\beta$-miR$34 \mathrm{a}-\mathrm{CCL} 22$ signaling-induced Treg cell recruitment promotes venous metastases of HBV-positive hepatocellular carcinoma. Cancer Cell (2012) 22(3):291-303. doi: 10.1016/j.ccr.2012.07.023

112. Wang D, Quiros J, Mahuron K, Pai CC, Ranzani V, Young A, et al. Targeting EZH2 Reprograms Intratumoral Regulatory $\mathrm{T}$ Cells to Enhance Cancer Immunity. Cell Rep (2018) 23(11):3262-74. doi: 10.1016/j.celrep.2018.05.050

113. Yu Q, Lou XM, He Y. Preferential recruitment of Th17 cells to cervical cancer via CCR6-CCL20 pathway. PloS One (2015) 10(3):e0120855. doi: 10.1371/journal.pone.0120855

114. Yu X, Yuan Z, Yang Z, Chen D, Kim T, Cui Y, et al. The novel long noncoding RNA u50535 promotes colorectal cancer growth and metastasis by regulating CCL20. Cell Death Dis (2018) 9(7):751. doi: 10.1038/s41419-018-0771-y

115. Vitiello GA, Miller G. Targeting the interleukin-17 immune axis for cancer immunotherapy. J Exp Med (2020) 217(1):1-11. doi: 10.1084/jem.20190456

116. Zhang Z, Tang H, Chen P, Xie H, Tao Y. Demystifying the manipulation of host immunity, metabolism, and extraintestinal tumors by the gut microbiome. Signal Transduct Target Ther (2019) 4:41. doi: 10.1038/ s41392-019-0074-5

117. Allen J, Sears CL. Impact of the gut microbiome on the genome and epigenome of colon epithelial cells: contributions to colorectal cancer development. Genome Med (2019) 11(1):11. doi: 10.1186/s13073-0190621-2

118. Raskov H, Søby JH, Troelsen J, Bojesen RD, Gögenur I. Driver Gene Mutations and Epigenetics in Colorectal Cancer. Ann Surg (2020) 271 (1):75-85. doi: 10.1097/sla.0000000000003393

119. Seth P, Hsieh PN, Jamal S, Wang L, Gygi SP, Jain MK, et al. Regulation of MicroRNA Machinery and Development by Interspecies S-Nitrosylation. Cell (2019) 176(5):1014-25.e12. doi: 10.1016/j.cell.2019.01.037

120. Wang Z, Hua W, Li C, Chang H, Liu R, Ni Y, et al. Protective Role of Fecal Microbiota Transplantation on Colitis and Colitis-Associated Colon Cancer in Mice Is Associated With Treg Cells. Front Microbiol (2019) 10:2498. doi: $10.3389 /$ fmicb.2019.02498

121. Donohoe DR, Holley D, Collins LB, Montgomery SA, Whitmore AC, Hillhouse A, et al. A gnotobiotic mouse model demonstrates that dietary fiber protects against colorectal tumorigenesis in a microbiota- and butyratedependent manner. Cancer Discov (2014) 4(12):1387-97. doi: 10.1158/21598290.Cd-14-0501

122. Schaupp L, Muth S, Rogell L, Kofoed-Branzk M, Melchior F, Lienenklaus S, et al. Microbiota-Induced Type I Interferons Instruct a Poised Basal State of Dendritic Cells. Cell (2020) 181(5):1080-96.e19. doi: 10.1016/ j.cell.2020.04.022

123. Routy B, Le Chatelier E, Derosa L, Duong CPM, Alou MT, Daillère R, et al. Gut microbiome influences efficacy of PD-1-based immunotherapy against epithelial tumors. Science (2018) 359(6371):91-7. doi: 10.1126/ science.aan3706

124. Choi HJ, Park JH, Park M, Won HY, Joo HS, Lee CH, et al. UTX inhibits EMT-induced breast CSC properties by epigenetic repression of EMT genes in cooperation with LSD1 and HDAC1. EMBO Rep (2015) 16(10):1288-98. doi: 10.15252/embr.201540244

125. Liang Y, Hu J, Li J, Liu Y, Yu J, Zhuang X, et al. Epigenetic Activation of TWIST1 by MTDH Promotes Cancer Stem-like Cell Traits in Breast Cancer. Cancer Res (2015) 75(17):3672-80. doi: 10.1158/0008-5472.Can-15-0930

126. Toh TB, Lim JJ, Chow EK. Epigenetics in cancer stem cells. Mol Cancer (2017) 16(1):29. doi: 10.1186/s12943-017-0596-9

127. Wainwright EN, Scaffidi P. Epigenetics and Cancer Stem Cells: Unleashing, Hijacking, and Restricting Cellular Plasticity. Trends Cancer (2017) 3 (5):372-86. doi: 10.1016/j.trecan.2017.04.004

128. Liu C, Kelnar K, Liu B, Chen X, Calhoun-Davis T, Li H, et al. The microRNA miR-34a inhibits prostate cancer stem cells and metastasis by directly repressing CD44. Nat Med (2011) 17(2):211-5. doi: 10.1038/nm.2284

129. Liu C, Liu R, Zhang D, Deng Q, Liu B, Chao HP, et al. MicroRNA-141 suppresses prostate cancer stem cells and metastasis by targeting a cohort of pro-metastasis genes. Nat Commun (2017) 8:14270. doi: 10.1038/ ncomms 14270

130. Cho MH, Park JH, Choi HJ, Park MK, Won HY, Park YJ, et al. DOT1L cooperates with the c-Myc-p300 complex to epigenetically derepress CDH1 transcription factors in breast cancer progression. Nat Commun (2015) 6:7821. doi: $10.1038 /$ ncomms8821

131. Casey SC, Tong L, Li Y, Do R, Walz S, Fitzgerald KN, et al. MYC regulates the antitumor immune response through CD47 and PD-L1. Science (2016) 352 (6282):227-31. doi: 10.1126/science.aac9935

132. Schreiber RD, Old LJ, Smyth MJ. Cancer immunoediting: integrating immunity's roles in cancer suppression and promotion. Science (2011) 331 (6024):1565-70. doi: 10.1126/science.1203486

133. Zhang D, Tang DG, Rycaj K. Cancer stem cells: Regulation programs, immunological properties and immunotherapy. Semin Cancer Biol (2018) 52(Pt 2):94-106. doi: 10.1016/j.semcancer.2018.05.001

134. Nowell PC. The clonal evolution of tumor cell populations. Science (1976) 194(4260):23-8. doi: 10.1126/science.959840

135. Hinohara K, Polyak K. Intratumoral Heterogeneity: More Than Just Mutations. Trends Cell Biol (2019) 29(7):569-79. doi: 10.1016/ j.tcb.2019.03.003

136. Matei D, Ghamande S, Roman L, Alvarez Secord A, Nemunaitis J, Markham MJ, et al. A Phase I Clinical Trial of Guadecitabine and Carboplatin in Platinum-Resistant, Recurrent Ovarian Cancer: Clinical, Pharmacokinetic, and Pharmacodynamic Analyses. Clin Cancer Res (2018) 24(10):2285-93. doi: 10.1158/1078-0432.Ccr-17-3055

137. Oza AM, Matulonis UA, Alvarez Secord A, Nemunaitis J, Roman LD, Blagden SP, et al. A Randomized Phase II Trial of Epigenetic Priming with Guadecitabine and Carboplatin in Platinum-resistant, Recurrent Ovarian Cancer. Clin Cancer Res (2020) 26(5):1009-16. doi: 10.1158/1078-0432.Ccr-19-1638

138. Lee V, Wang J, Zahurak M, Gootjes E, Verheul HM, Parkinson R, et al. A Phase I Trial of a Guadecitabine (SGI-110) and Irinotecan in Metastatic Colorectal Cancer Patients Previously Exposed to Irinotecan. Clin Cancer Res (2018) 24(24):6160-7. doi: 10.1158/1078-0432.Ccr-18-0421

139. Stein EM, Garcia-Manero G, Rizzieri DA, Tibes R, Berdeja JG, Savona MR, et al. The DOT1L inhibitor pinometostat reduces H3K79 methylation and has modest clinical activity in adult acute leukemia. Blood (2018) 131 (24):2661-9. doi: 10.1182/blood-2017-12-818948

140. Yap TA, Winter JN, Giulino-Roth L, Longley J, Lopez J, Michot JM, et al. Phase I Study of the Novel Enhancer of Zeste Homolog 2 (EZH2) Inhibitor GSK2816126 in Patients with Advanced Hematologic and Solid Tumors. Clin Cancer Res (2019) 25(24):7331-9. doi: 10.1158/1078-0432.Ccr-18-4121

141. Harb W, Abramson J, Lunning M, Goy A, Maddocks K, Lebedinsky C, et al. $42 \mathrm{O}$ - A phase 1 study of CPI-1205, a small molecule inhibitor of EZH2, preliminary safety in patients with B-cell lymphomas. Ann Oncol (2018) 29: iiii. doi: 10.1093/annonc/mdy048.001

142. Italiano A, Soria JC, Toulmonde M, Michot JM, Lucchesi C, Varga A, et al. Tazemetostat, an EZH2 inhibitor, in relapsed or refractory B-cell nonHodgkin lymphoma and advanced solid tumours: a first-in-human, openlabel, phase 1 study. Lancet Oncol (2018) 19(5):649-59. doi: 10.1016/s14702045(18)30145-1

143. Morschhauser F, Tilly H, Chaidos A, McKay P, Phillips T, Assouline S, et al. Tazemetostat for patients with relapsed or refractory follicular lymphoma: an open-label, single-arm, multicentre, phase 2 trial. Lancet Oncol (2020) 21 (11):1433-42. doi: 10.1016/s1470-2045(20)30441-1

144. Ferrari AC, Alumkal JJ, Stein MN, Taplin ME, Babb J, Barnett ES, et al. Epigenetic Therapy with Panobinostat Combined with Bicalutamide Rechallenge in Castration-Resistant Prostate Cancer. Clin Cancer Res (2019) 25(1):52-63. doi: 10.1158/1078-0432.Ccr-18-1589

145. van Tilburg CM, Milde T, Witt R, Ecker J, Hielscher T, Seitz A, et al. Phase I/ II intra-patient dose escalation study of vorinostat in children with relapsed solid tumor, lymphoma, or leukemia. Clin Epigenet (2019) 11(1):188. doi: 10.1186/s13148-019-0775-1

146. Galanis E, Anderson SK, Miller CR, Sarkaria JN, Jaeckle K, Buckner JC, et al. Phase I/II trial of vorinostat combined with temozolomide and radiation therapy for newly diagnosed glioblastoma: results of Alliance N0874/ABTC 02. Neuro Oncol (2018) 20(4):546-56. doi: 10.1093/neuonc/nox161

147. Lübbert M, Grishina O, Schmoor C, Schlenk RF, Jost E, Crysandt M, et al. Valproate and Retinoic Acid in Combination With Decitabine in Elderly 
Nonfit Patients With Acute Myeloid Leukemia: Results of a Multicenter, Randomized, $2 \times 2$, Phase II Trial. J Clin Oncol (2020) 38(3):257-70. doi: 10.1200/jco.19.01053

148. O'Connor OA, Falchi L, Lue JK, Marchi E, Kinahan C, Sawas A, et al. Oral 5azacytidine and romidepsin exhibit marked activity in patients with PTCL: a multicenter phase 1 study. Blood (2019) 134(17):1395-405. doi: 10.1182/ blood.2019001285

149. Gaillard SL, Zahurak M, Sharma A, Durham JN, Reiss KA, SartoriusMergenthaler S, et al. A phase 1 trial of the oral DNA methyltransferase inhibitor CC-486 and the histone deacetylase inhibitor romidepsin in advanced solid tumors. Cancer (2019) 125(16):2837-45. doi: 10.1002/ cncr.32138

150. Levy BP, Giaccone G, Besse B, Felip E, Garassino MC, Domine Gomez M, et al. Randomised phase 2 study of pembrolizumab plus CC-486 versus pembrolizumab plus placebo in patients with previously treated advanced non-small cell lung cancer. Eur J Cancer (2019) 108:120-8. doi: 10.1016/ j.ejca.2018.11.028

151. Gray JE, Saltos A, Tanvetyanon T, Haura EB, Creelan B, Antonia SJ, et al. Phase I/Ib Study of Pembrolizumab Plus Vorinostat in Advanced/Metastatic Non-Small Cell Lung Cancer. Clin Cancer Res (2019) 25(22):6623-32. doi: 10.1158/1078-0432.Ccr-19-1305

152. Rodriguez CP, Wu QV, Voutsinas J, Fromm JR, Jiang X, Pillarisetty VG, et al. A Phase II Trial of Pembrolizumab and Vorinostat in Recurrent Metastatic Head and Neck Squamous Cell Carcinomas and Salivary Gland Cancer. Clin Cancer Res (2020) 26(4):837-45. doi: 10.1158/1078-0432.Ccr-19-2214

153. Di Giacomo AM, Covre A, Finotello F, Rieder D, Danielli R, Sigalotti L, et al. Guadecitabine Plus Ipilimumab in Unresectable Melanoma: The NIBIT-M4 Clinical Trial. Clin Cancer Res (2019) 25(24):7351-62. doi: 10.1158/10780432.Ccr-19-1335
154. Wang X, Brea LT, Yu J. Immune modulatory functions of EZH2 in the tumor microenvironment: implications in cancer immunotherapy. Am J Clin Exp Urol (2019) 7(2):85-91.

155. Béguelin W, Teater M, Meydan C, Hoehn KB, Phillip JM, Soshnev AA, et al. Mutant EZH2 Induces a Pre-malignant Lymphoma Niche by Reprogramming the Immune Response. Cancer Cell (2020) 37(5):65573.e11. doi: 10.1016/j.ccell.2020.04.004

156. Oki Y, Buglio D, Zhang J, Ying Y, Zhou S, Sureda A, et al. Immune regulatory effects of panobinostat in patients with Hodgkin lymphoma through modulation of serum cytokine levels and T-cell PD1 expression. Blood Cancer J (2014) 4(8):e236. doi: 10.1038/bcj.2014.58

157. Medon M, Vidacs E, Vervoort SJ, Li J, Jenkins MR, Ramsbottom KM, et al. HDAC Inhibitor Panobinostat Engages Host Innate Immune Defenses to Promote the Tumoricidal Effects of Trastuzumab in HER2(+) Tumors. Cancer Res (2017) 77(10):2594-606. doi: 10.1158/0008-5472.Can-16-2247

158. Chiappinelli KB, Zahnow CA, Ahuja N, Baylin SB. Combining Epigenetic and Immunotherapy to Combat Cancer. Cancer Res (2016) 76(7):1683-9. doi: 10.1158/0008-5472.Can-15-2125

Conflict of Interest: The authors declare that the research was conducted in the absence of any commercial or financial relationships that could be construed as a potential conflict of interest.

Copyright (c) 2021 Yang and Wang. This is an open-access article distributed under the terms of the Creative Commons Attribution License (CC BY). The use, distribution or reproduction in other forums is permitted, provided the original author(s) and the copyright owner(s) are credited and that the original publication in this journal is cited, in accordance with accepted academic practice. No use, distribution or reproduction is permitted which does not comply with these terms. 